\title{
Lapsele laulmise fenomen koduses kasvatuskultuuris
}

\author{
Airi Liimets \\ Tallinna Ülikooli kasvatusfilosoofia külalisprofessor \\ airi_liimets@yahoo.de \\ Külli Erimäe \\ Tallinna Kadaka lasteaia muusikaõpetaja, kasvatusteaduste magister \\ kyllierimae@gmail.com
}

\begin{abstract}
Teesid: Artikli keskmes on küsimus, missugune on lapsele laulmise kui fenomeni positsioon ja tähendus koduses kasvatuskultuuris tänapäeva Eestis. Teoreetilise analüüsi tulemusel käsitame kasvatuskultuuri kommunikatiivse kasvatustegelikkusena ning seda konstitueerivate komponentidena kultuurisümboleid ja rituaale. Empiirilise uurimistöö kaudu otsime lisaks põhiprobleemile vastust küsimustele: a) Mida on võimalik kasvatuskultuuri vaatepunktist järeldada meie 2016. aasta uuringu andmete ja Anu Visseli aastaist 1990-2000 pärinevate andmete võrdlusest? b) Kas empiirilise uurimistöö tulemused võimaldavad rikastada ka teoreetilisi käsitlusi kasvatusest kui kultuurifenomenist? Võrdlus Visseli andmetega lubab väita, et lapsele laulmise fenomen on kultuurisümbol, mis kõneleb püsivaloomulisest üle aegade ulatuvast kodusest kasvatuskultuurist. Lapsevanemate eelistatud sama laulurepertuaar on kulgenud läbi aastakümnete. Hällilaulude laulmist võiks ka nimetada globaalseks rituaaliks kasvatuskultuuris, sest sellega seoses tuleb ilmsiks enamik rituaali iseloomustavaid tunnuseid.
\end{abstract}

Märksõnad: Eesti, empiiriline analüüs, kodune kasvatuskultuur, lapsele laulmine, lastelaul, võrdlusuurimus

\section{Sissejuhatuseks}

Mis tahes kultuuri jätkuvus ja elujõulisus sõltub lõppkokkuvõttes eri põlvkondade omavahelisest sidususest ning seda tagavast kasvatusest kui vastastikusest mõjutamisest. Laiemalt mõeldes sõltub kultuuri jätkuvus seega kasvatuskultuurist kui kommunikatiivsest kasvatustegelikkusest ning selle kaudu vahendatavatest sümbolitest. Inimeste kultuurimälu ühe olulisima sümbolina käsitab näiteks Ruprecht Mattig (2006) muusikat, kuna see seostub nii emotsioonide ja tujude kui ka mentaalsete representatsioonidega teadvuses. Eesti kultuur oma iseärasustega on öeldule väga heaks kinnituseks, kuna eestlaste identiteedi olulisimaks väljenduseks läbi aegade on ikka peetud laulmist ning 1869. aastal alguse saanud laulupeotraditsiooni. Selle traditsiooni jätkuvusele võib kindlasti kaasa aidata laulmise kui tegevuse juurdumine koduses kasvatuskultuuris igapäevaelu loomupärase osana. 
Öeldust tulenevalt on olnud meie uurimistöö põhiprobleemiks küsimus, missugune on lapsele laulmise positsioon ja tähendus koduses kasvatuskultuuris tänapäeva Eestis. Antud küsimusele vastamiseks on loogiline saada kõigepealt selgust selles, kuidas: a) piiritleda kasvatust kultuurifenomenina ehk mis seda konstitueerib; b) piiritleda lapsele laulmine ja lastelaul kultuuriliste fenomenidena. Nimetatud kaks küsimust on käsitatavad meie teoreetilise uurimistöö eesmärkidena. Empiirilise uurimistöö kaudu otsime lisaks põhiprobleemile vastust veel kahele küsimusele: a) Mida on võimalik kasvatuskultuuri vaatepunktist järeldada meie andmete ja etnomusikoloog Anu Visseli vastavate varasemate - aastaist 1990-2000 pärinevate - andmete võrdlusest? b) Kas meie empiirilise uurimistöö tulemused võimaldavad rikastada ka teoreetilisi käsitlusi kasvatusest kui kultuurifenomenist?

\section{Kasvatuskultuur - märk kommunikatiivsest kasvatustegelikkusest}

Inimene kui homo culturalis on loomult kultuurimärkide looja ja nende kasutaja (Danesi \& Perron 2005). Kultuurimärgid tagavad kultuuri sidususe. Nende märkide tähendused tekivad kommunikatsioonis ning igasugune kommunikatsioon on alati märgiline ehk semiootiline. Märk on alati vahendav. See vahendab reaalsust meie ümber ja meie sees (Sonesson 1999). Me sünnime teatud tähistamissüsteemi, mis määrab suuresti selle, kuidas me ümbritsevat maailma vaatleme ja mõistame.

Kasvatusfilosoof Airi Liimets (1999; 2009) on filosoofiliselt mõeldes määratlenud kasvatust inimese ja olemise diferentsina, rõhutades seeläbi, et kasvatus on mõistetav üksnes kui suhte- ning piirifenomen inimese ja oleva olemise vahel, mis sellisena kaht nimetatud poolust omavahel ühtaegu seob ja eristab. Inimese ja olemise dialoogilises protsessis realiseeruvat heideggerlikult väljendudes nende vastastikune ülesandelisus. Järelikult on kummagi osapoole (inimese ja oleva olemise) ülesandeks tagada kasvatuse jätkuv eksistents. Nõnda mõeldes osutub kasvatus põhjapanevaks fenomeniks, mis tagab nii olemise kui ka inimese kestmise; mis hoiab üleval kogu olemasolemise koordinaadistikku. Seega võiks ka öelda, et mis tahes kultuurivaldkond - muusikakultuur, söömiskultuur, teatrikultuur jm - pole võimalik kasvatuskultuurita, mis võib (nagu kultuur üldse) olla vaadeldav märgilise ja kommunikatiivse fenomenina.

Öelduga haakub hästi kasvatusteadlase Jüri Orni (1998) idee, et kasvatuskultuur on mõistetav kasvatustegelikkuse vahendusel. Kasvatustegelikkus omakorda on aga Orni (ibid.: 17) järgi määratletav kui "representatsioon sellest, mida me kasvatuseks peame, mida kasvatuse all mõistame ja kuidas oma 
kasvatuslikke kavatsusi realiseerime. Kasvatustegelikkus on osa sotsiaalsest tegelikkusest, kusjuures tegelikkus on käsitatav kui vahendatud reaalsus". Seega "kasvatustegelikkus saab "tegelikuks" esmajoones subjektiivse reaalsusena, mis avaneb meile selle kaudu, kuidas inimesed käsitavad kasvatust ja kasvatamist" (ibid.: 13). A. Liimetsa eespool nimetatud filosoofilise käsitlusega kasvatusest kui diferentsist ja piirifenomenist haakuvad hästi kõik need üldkasvatusteaduslikud teooriad (nt Värri 2002; Puolimatka 1999 jt), kus väidetakse, et reaalsuses ilmneb kasvatus eelkõige inimestevahelise interaktsioonina ning peamiselt sugupõlvedevahelisena (nt Lahikainen \& Punamäki \& Tamminen 2008).

Inger Kraavi (1998) järgi inimesed, kes kasvavad samal ajal samasugustes oludes ja kogevad samu ajaloolisi sündmusi, arenevad mingis suhtes sarnaselt. Põlvkond on inimesed, kelle haridus, veendumused, elukogemused, harjumused ja tavad on omandatud ühesugustes ajaloolistes oludes. Nad on olnud ka osalised samades kultuuritraditsioonides, nii et põlvkonnal tekib ühine teadvus ja sarnasel viisil organiseerunud kogemusmaailm. Küll ühel ja samal ajal, kuid eri kohtades ja oludes kasvavail inimestel on teatud põlvkonnaasend, põlvkonnavõimalus, aga neil puuduvad ühised kogemused. Uus põlvkond tekib alles osavõtmise ja tegevuste, mitte ainult teatud vanuserühma kuulumise kaudu. Põlvkonna kujunemisel on oluline ühises kasvukeskkonnas tegutsemine, samade empiiriliste kogemuste läbielamine, igapäevase interaktiivse kasvatussuhte omamine ja arendamine, kasvatusväärtuste vahendamine, kasvatuspõhimõtete edasiandmine põlvkondade järjepidevuse säilitamiseks. Põlvkonna arengu seisukohalt on sealjuures olulised just need sündmused ja olud, mis on pannud pitseri vastava põlvkonna noorusele.

Eelnevale toetudes võime järelikult väita, et põlvkondadevaheline interaktsioon ning kasvatuslik suhe on mõistetavad kommunikatiivse kasvatustegelikkusena nii subjektiivses reaalsuses (st representatsioonina teadvuses) kui ka meid ümbritsevas kasvukeskkondlikus reaalsuses. Mõlemal juhul on kasvatuskultuur kultuurimärgina määratletav kasvatussuhte kaudu, mida võiks käsitada ka kasvatuskultuuri vormilise aspektina. Olgu seda vormi loovaks koordinaadistikuks siis kas inimene ja olemine kui sellised (vrd Liimets 1999) või erinevad inimpõlvkonnad teatud ajastul (Kraav 1998 jt).

Kasvatuskultuuri sisulist aspekti võib seostada väärtusmaailmadega, kasvatusväärtustega. Jüri Orn (1998) on samuti rõhutanud, et kasvatus lähtub teatud väärtustest ja kasvatusprotsessi ehk kasvatamist võib mõista kui väärtustamist, mille käigus kujuneb inimese väärtuseline suhe teda ümbritsevasse ja iseendasse. Kui kasvatus on inimese suhe kasvavasse ja arenevasse, siis kasvatamine on selle suhte realiseerimine. Väärtused võivad püsida kaua muutumatutena ning siis muutuda äkki ja hüppeliselt. Varases lapsepõlves 
on kõige vahetumaks kasvukeskkonnaks perekond, kus laps võtab erinevaid väärtusi omaks spontaanselt igapäevaste ühistegevuste käigus. Kodu ongi läbi aegade olnud see institutsioon, tänu millele kandub ajastust ajastusse edasi kultuur - inimeksistentsi iseloomustav viis mõelda, toimetada, väärtustada, otsustada. Kasvatusväärtuste suhtelist püsivust ja jätkuvust kultuuris üle aegade rõhutavad ka Maarit Silvén ja Anna Kouvo (2008: 102-103), kui nad väidavad, et lapse arengut perekonnas mõjutab tugevalt nende vanemate suhe omakorda enda vanematega. Airi Liimetsa (2004) järgi on üks võimalusi (kasvatus)kultuuri mõistmiseks õppida tundma inimeste elustiili, mis hõlmab nii päev-päevalt korduvaid söömistavasid, riietumist, ehituskunsti, sotsiaalsete gruppide suhtlemisviise, kombeid ja religioosset käitumist jm. Niisiis võime väita, et nii iga laps kui ka täiskasvanu on tema koduse kasvatuskultuuri väljendus ja peegel.

Iris Nentwig-Gesemann (2006) on uurinud kasvatusprotsesside spetsiifilisi aspekte perekonnas ja leidnud, et pereliikmed mõistavad üksteist kuidagi loomulikult, mis põhineb nende jagatud ja tavapärastel kogemustel ühises kogemuslikus ruumis. Meie-tunde tekkimisele aitavad kaasa pidupäevade koosveetmised, sünnipäevade tähistamised, vanavanemate ja lahkunud pereliikmete meelespidamised, oma pere loo tundmine - oma vanemate ja vanavanemate elu ja tegudega kursisolemine ning ühised tegevused ja hobid. Võib kõnelda üldmentaalsest habitusest ehk perekonna harjumuspärasest stiilist olemas olla. Habitus garanteerib tegevuste jätkumise. Tegevuses osalejate elukogemuse rekonstrueerimine avab aga ligipääsu perekonna harjumuspärase stiili kirjeldusele ning selle miljööspetsiifilise tekke selgitusele. Habitus loob reegleid ning sisaldab teatud reegleid, mida järgitakse.

Niklas Luhmanni (vt Luhmann 2009; vrd ka Midtsundstad 2006) sotsiaalsete süsteemide teooria kohaselt kommunikatsioon kui struktuur tekib süsteemi elementide funktsioonide erinevustest. Selliseid kommunikatiivseid struktuure võib tähistada ka semantiliste koodidena ehk kultuurisümbolitena. Kultuurisümbolid kanduvad aga kõige paremini edasi tänu ritualiseerimisele (Danesi \& Perron 2005) ning rituaalides osalejate kultuurimälule. Järelikult koosneb ka kasvatuskultuur kui kommunikatiivne struktuur kultuurisümbolitest, mis kõige paremini saavad tulla ilmsiks erinevate rituaalide kaudu.

Rituaali võib mõista sümboolse tähendusega reeglitest juhitud tegevusena, mis suunab selles osalejate tähelepanu, mõtted ja emotsioonid teatud objektidele (asjad, tegevused, inimesed, tegevusproduktid jne), mida antud inimkooslus peab eriti tähendusrikkaks (Mattig 2006). Tänu sümbolilisusele hakkavad rituaalid korrastama enda ümber uut kogemust. Sümbol on kollektiivse mälu mehhanism, mis hakkab ka ise muutuma tänu interaktiivsusele vastavas 
kultuuris. Kultuurisümbolite tunnuseks (vrd Lotman 1999) on sealjuures asjaolu, et nad ei kuulu kunagi vaid mingisse ühte sünkroonsesse aegruumi, vaid läbivad kultuuri selle vertikaalteljel - tulles minevikust ja lahkudes tulevikku. Sümbol on vahendajaks sünkroonia ja kultuurimälu vahel. Ühelt poolt püsib kultuurisümbol tänu kordumistele läbi aegade invariantsena. Teiselt poolt korreleerub kultuurisümbol aktiivselt sünkroonse kultuurikontekstiga, muundudes ka ise selle mõjul. Invariantsus realiseerubki läbi variatiivsuse sümboli eri variantidena. Sümboli tähenduslikkus tuleb ilmsiks üksnes selle kasutamisel.

Saksa kasvatusfilosoofi Christoph Wulfi (2006) järgi võib kasvatusrituaalide klassifitseerimisel lähtuda ühe võimalusena neile aluseks olevate tegevusmotiivide diferentseerimisest. Sellest tulenevalt on näiteks eristatavad:

a) üleminekuperioodide rituaalid (sünd ja lapsepõlv, noorukiiga, abielu, surm);

b) kalendrirituaalid (jõulud, sünnipäevad, mälestusteenistused, riiklikud pühad);

c) intensiivistamisrituaalid (rongkäigud, peod, armastus, seksuaalsus);

d) ülestõusurituaalid (vabastusliikumised, ökoloogilised liikumised, noorte kombed);

e) interaktsioonirituaalid (tervitamised, lahkumised, konfliktid).

Rituaalidel üldse ja ka rituaalidel kasvatuses on eristatavad demonstreeriv, mänguline, ekspressiivne, spontaanne ja sümboolne aspekt; nad on reeglipärased ja ilmnevad korrapäraselt (Nentwig-Gesemann 2006). Christoph Wulfi ja Jörg Zirfase (2004: 18) kohaselt iseloomustab rituaale seitse olulist funktsiooni. Rituaalid on kommunikatiivsed, identifitseeriv-transformeerivad, mäluloovad, filosoofilised (eritledes elu ja surmaga seotut), transtsendentaal-maagilised (osutades nn pühale elusfäärile), diferentse loovad ja töötlevad. Ingrid Kellermann (2006) rõhutab eriliselt rituaalide mitmetähenduslikkust ja polümorfsust. Tema järgi toimivad rituaalidele omistatavad tunnused vastastikuses interaktsioonis, on ambivalentsed ja diferentsed, näiliselt vastandlikud ja sõltuvad kommunikatsioonist kui sümbolitele tuginevast suhtlemisprotsessist.

Öeldust tulenevalt ning osaliselt C. Wulfile (2006) tuginedes oleme sõnastanud ka teatud hulga kasvatusrituaali iseloomustavaid tunnuseid, vaadeldes neid koosnevana sisuliselt üht tervikut moodustavatest vastandlikest fenomenidest, mis on omavahel ühendatud dimensionaalselt mõistetud liikumisteega. Sõltuvalt positsioonist sel liikumisteel määratleb üks või teine neist vastandlikest poolustest antud ajahetkel vastavat rituaali kas rohkem või vähem. Kirjeldatud viisil mõistetavad rituaali tunnused on meie sõnastatuna järgmised: 
1) seotus kollektiivse kultuurimäluga versus avatus sünkroonsele sotsiaalsele kultuuriruumile;

Ka Juri Lotmani (1991) järgi iseloomustab rituaali kui sellist kommunikatsioon sünkroonse ruumaja ning kultuuritraditsiooni vahel. Kasvatusrituaalid ja sotsiaalne elu on perekonnas ühendatud (Wulf 2006) ning rituaale tuleks mõista kui interaktsiooni mustreid, mida praktiseeritakse ja sisendatakse kordamise ja imiteerimise kaudu.

2) taastootlikkus/imiteeritavus, regulaarsus versus plahvatuslikkus;

Rituaalide taastootlikkus on seotud sotsiaalsete suhetega, võnkudes konfliktsuse ja integratsiooni vahepeal (Werler \& Wulf 2006). Enamiku oma sotsiaalsetest kompetentsustest õpib inimene matkimise abil. Sealjuures on iga kordamine omamoodi transformatsioon ning aeg-ajalt isegi uue terviku loomine. Juri Lotmani (2005) ideid kohandades moodustub kasvatuskultuur erineva kiirusega arenevatest kihtidest, nii et sünkroonselt toimivas struktuuris eksisteerivad üheaegselt nii uuenduslikkust tagavad plahvatuslikud kui ka järjepidevust kindlustavad korduvad protsessid. Kui tekib plahvatusmoment, hakkab mingi teatud rituaal kaduma. Kerkivad esile uued, vanad teisenevad, kuid see ei tähenda nende täielikku hävimist. Plahvatusega kaasneb kogu süsteemi informatiivsuse järsk suurenemine. Protsessi pöördepunktiks on plahvatuse ammendumishetk. Tekivad uued tähendused, mis ometi sisaldavad tänu rituaali kommunikatiivsusele midagi ka vanast.

3) loovus ja ekspressiivsus versus fundamentaalsed väärtused;

4) mänguline versus "tõeline" tegelikkus;

5) religioossus, emotsionaalsus versus füüsilisus;

6) seotus kommete, harjumuste ja eetilisusega versus manipuleeritavus võimu abil;

Kasvatajal on võimalus ja vabadus arendada ja avardada inimese eetilisust, aga oma suhtelise võimupositsiooni kaudu sisendada ka ideoloogiaid ning nende abil lapsega manipuleerida.

Rituaalides on kõik eespool nimetatud tunnusjooned enamasti esindatud üheaegselt ning integreerituna. Teoreetilise analüüsi tulemusel võime kokkuvõtteks öelda, et kasvatus - käsitatud kultuurilise fenomenina ehk kasvatuskultuurina - on mõistetav kommunikatiivse kasvatustegelikkuse vahendatud märgilise fenomenina, mille vormi (kasvatussuhe kui selline) ja sisu (kasvatusväärtused) loovad erinevad kultuurisümbolid, mis võivad, kuid tingimata ei pruugi olla organiseerunud rituaalideks. 


\section{Lapsele laulmine koduses kasvatuskultuuris}

\subsection{Lapsele laulmisest ja lastelaulust kultuuris}

Hoolimata sellest, et vanemlus on kultuuriliselt konstrueeritud ja et erinevate maade kasvatustraditsioonid on erinevad (Harkness \& Super 2001: 253), on lapsele laulmine levinud kogu maailmas (Trehub, Unyk \& Trainor 1993a: 207). See ei mõjuta ainult last, vaid ka lauljast lapsevanemat ennast, kuna vähendab väidetavalt ta stressitaset (Custodero, Britto \& Brooks-Gunn 2003; Loewy \& Stewart \& Dassler \& Telsey \& Homel 2013).

Lapsele laulmine on osa sotsialiseerimisprotsessist ja enkulturatsioonist ning peamine muusikaline tegevus lapse esimestel eluaastatel (Vissel 1996; Custodero \& Britto \& Brooks-Gunn 2003; Ilari 2005). Ellen Dissanayake (2001) peab imiku ja ema suhtlust rituaalseks käitumiseks, kuna see on sarnane terves maailmas. Täiskasvanu püüab mitteteadlikult hääletooni, prosoodia abil tõmmata endale lapse tähelepanu. Imik vastab miimika, emotsioonide ja kehakeele abil. Lapsevanemate isiklikud muusikalised eelistused tavaliselt lastemuusikat ei sisalda, küll aga võib lasterepertuaari invasiooni perekonda täheldada koos lapse sünniga (Ilari \& Moura \& Bourscheidt 2011). Lapsevanem hakkab last muusikaliselt kasvatama seda endale omaette eesmärgiks seadmata, nagu sageli üldse kodune kasvatus toimibki implitsiitselt ja lähtub intuitsioonist. Seega on ka muusikakasvatus märk kommunikatiivsest kasvatustegelikkusest.

Uuringud (nt Trehub \& Unyk \& Trainor 1993b) näitavad, et väikelapsele laulmist eristatakse tavapärasest laulmisest. Kui paluti inimestel tuvastada lapsele suunatud laulmist, siis suurima erinevusena nimetati emade hääletooni laulmisel, kusjuures naised olid meestest selles suhtes tundlikumad. Väikelapsele laulmist iseloomustab kõrgem helistik, aeglasem tempo, pikemad pausid fraaside vahel ja armastavam laulmisviis (Trainor \& Clark \& Huntley 1997). Sarnaselt hoidjakeelele ${ }^{1}$ sõltuvad lapsele laulmise iseärasused lapse vanusest. Suuremale lapsele lauldes hakkab enam rolli mängima artikulatsioon. Imikule lauldakse kõrgemalt. Väikelapsed ise eelistavad rõõmsamat esitust ega tee vahet hoidjakeelel ja lapsele suunatud laulmisel, kui esitus on ühtviisi positiivne ja emotsionaalne (Corbeil \& Trehub \& Peretz 2013).

Lapsele laulmise sagedus sõltub lapse vanusest. Lapsele laulmist, olenemata tema east, peavad oluliseks kõik vanemad (Vissel 2005), kuid eelkõige lauldakse imikule ja väikelapsele (Custodero \& Britto \& Brooks-Gunn 2003; Custodero \& Johnson-Green 2003). Suuremate laste puhul lähevad aga erinevate maade uurimuste andmed lahku. Eestis eelkooliealiste laste laulmist uurinud Anu Visseli (2005) andmetel laulab enamik lapsevanemaid lapsele mõni kord nädalas, igapäevaselt tunduvalt harvem. Ameerika Ühendriikides 
nelja-aastaste laste vanemate hulgas läbiviidud küsitluse põhjal laulis suurem osa vanemaid iga päev (Mehr 2014). Austraalias alla nelja-viieaastaste laste vanemate hulgas tehtud küsitlus kinnitas aga, et igapäevaseid lapsele lauljaid oli seal küsitletutest kõige vähem ja enamik vanemaist laulis kord nädalas või veelgi harvem (de Vries 2009). Mainitud andmetesse (eriti USA omadesse) tuleks meie arvates suhtuda veidi skeptiliselt, sest lapsele laulmine on ideaalse vanema kuvandisse juurdunud nähtus ja igaüks tahab end näidata paremana tegelikkusest. Seega siis võib arvata, et antud tulemus on pigem lapsevanema soovunelm kui reaalsus. Lapsele laulmine sõltub ka lapse sünnijärjekorrast (Custodero \& Britto \& Brooks-Gunn 2003; Ilari 2005). Esmasündinuile lauldakse rohkem kui järgmistele lastele peres.

Lapsele laulab kodus enamasti ema, vanaemade ja isade roll on tunduvalt väiksem (Vissel 2005; Trehub et al. 1997; Custodero \& Britto \& Brooks-Gunn 2003). Rassilisest ja soolisest aspektist vaadatuna laulab igapäevaselt kõige enam nn valgest rassist ema, "valge" isa aga kõige vähem. Samas kui nn tumeda rassi (ingl non-hispanic black) esindajate hulgas on igapäevaste lastele lauljate hulk emade ja isade osas võrdne ja üsna lähedane "valgete" emade tulemusele (Custodero \& Britto \& Brooks-Gunn 2003). Antud tulemused kipuvad tõestama valitsevat "valge mehe" diskursust, kus mehelike tegevuste hulka ei kuulu lastele laulmine. Endaga samast soost lapsele laulavad mõlemad vanemad mängulisemalt kui vastassoost lapsele, eriti suur vahe on isade laulmisel, kes poistele laulavad mängulisemaid laule ja tüdrukutele pigem hällitavaid ja rahustavaid laule (Trehub \& Hill \& Kamenetsky 1997).

Kõrgema haridusega vanemad laulavad oma lastele rohkem, kuid vanemate vanus laulmist ei mõjuta (Custodero \& Britto \& Brooks-Gunn 2003). Erinevate uuringute tulemuste valgel on andmed lapsevanema eelneva muusikalise hariduse mõjust lastele laulmisele vastukäivad. Mõnede uuringute järgi soodustavad vanemate muusikalised eelteadmised lastele laulmist (Custodero \& Johnson-Green 2003), samas mõni uuring ei leia muusikahariduse olemasolu ning lastele laulmise vahel mingit seost (Ilari 2005; Ilari \& Moura \& Bourscheidt 2011). Lapsele laulmine ei ole seotud muusikalise enesehinnanguga. Kuigi paljud emad arvavad, et neil ei ole lauluhäält, laulavad nad oma lastele sellest hoolimata (Street \& Young \& Tafuri \& Ilari 2003). Sissetuleku suurus ei mõjuta isade laulmist, ent suurema sissetulekuga emad laulavad rohkem (Custodero \& Britto \& Brooks-Gunn 2003). Vastukäivad on erinevate uuringute andmed ka laulmise ja vanemate tööhõive seose kohta. Kanadas laulavad töötavad emad kodustest ja õppivatest emadest rohkem (Ilari 2005), aga Ameerika Ühendriikides laulavad osalise tööajaga või kodused emad-isad täistööajaga vanematest enam (Custodero \& Britto \& Brooks-Gunn 2003). 
Lastelaule eesti vanemas rahvalaulus (nagu ka ahellaule, itke, loitse, hõikeid jms) ei olegi tavaliselt nimetatud lauludeks ega nende esitust laulmiseks. Neid esitati kas tavalises kõnes, vabarütmilise retsitatiivina või siis skandeeriti kindlas taktimõõdus, kuid ilma kindlakujulise meloodiata. Laulmiseks nimetati hällilaulude ja äiutuste esitust. Lauludeks nimetatakse eesti keeles ka lindude häälitsuste imitatsioone (Rüütel 1999). Laulu ja viisi eristamisest eesti keeles annavad märku ka mitmete ajalooliste kogumike pealkirjad. Näiteks Johann Woldemar Jannseni 1860. aastal välja antud "Eesti laulik" on sõnade kogumik ja alles 1862. aastal andis ta välja "Eesti lauliku viisiraamatu", mis sisaldab noote, kusjuures nootide juurde olid lisatud ainult esimese salmi sõnad. Tänapäevalgi mõistetakse Eestis laulmist ja laulu loomist pigem verbaalse ülesandena, kus meloodial on teisejärguline koht (Raju 2015).

Lastelaulu defineerimine on eesti keeles olnud problemaatiline kuni tänapäevani. Lastelaulu tänapäevase määratluse aluseks on eelkõige teadmine lastelaulust kui vokaalžanrist. Seda mõistetakse enamasti autorilauluna, mille on kirjutanud helilooja (s.t täiskasvanu) ja mis on mõeldud lastele laulmiseks. Lastelaulu liigitamisviis eesti vanemas rahvalaulus viitab aga selle defineerimisele lähtuvalt rahvamuusikast, mille määratlemisel on oluline muusikalise käitumise ja esituse situatsioon ning funktsioon (Särg 2002: 26). Tänapäeval ei peeta paljusid rahvamuusika lastelaululiike (nt liisklugemisi, narritamissõnu) enam lauludeks. Kogu seda repertuaari nimetakse lastepärimuseks, lastefolklooriks või lastekultuuriks (Vissel 2004: 12-15). Eesti uuem lastelaul on valdavalt täiskasvanukeskne autorilaul ning on täienenud oma esmase funktsiooni kaotanud laululiikide (mängu-, tantsu-, muinasjutulaulude jt) arvel.

Lapsevanemate lauluvara iseloomustab traditsioonilisus. Regilaulude kogumispraktika Eestis näitab, et vanade rahvalaululiikide lastelaulud on inimeste mälus säilinud kõige kauem (Vissel 2005). Lapsevanemad on teatud lastelaulud selgeks õppinud oma lapsepõlves. Lastelaulude õpetajatena on olnud oluline roll vanaemadel. Põlvkondade lõikes ei erine lastelaulud oluliselt eelmise põlve omadest. Välja on kujunenud populaarsemate lastelaulude ring, mida järgmisele põlvele edasi õpetatakse (Vissel 1996). Nüüdisaegsetele Eesti lapsevanematele ei ole lapsele lauldes oluline laulude päritolu (rahvalaul, rahvalik laul, autorilaul), lastelauluks on eelkõige nn vana tuntud eesti laul (Vissel 2004: 29). ${ }^{2}$ Lastelaulu iseloomustab rahvuskesksus (ibid.). Brasiilia lapsevanemad laulavad oma lastele peamiselt brasiilia lastelaule (Ilari \& Moura \& Bourscheidt 2011) ning Ameerika Ühendriikide lastevanemate lastelaulud on anglo-ameerika päritolu (Bergeson \& Trehub 1999; Trehub et al. 1997). Omakultuuri mõju on täheldatud ka Kanada uusimmigrantidest lapsevanemate lauluvalikus, mis on valdavalt emakeelne (Ilari 2005). Lastele lauldavate laulude hulka kuulusid eesti vanemas rahvalaulus: 1) äiutused ja hällilaulud, 
2) mängitus- ehk hüpituslaulud, 3) lastele loetud loitsud; 4) laulud kitsamas mõistes (Särg \& Ilmjärv 2009).

Hälli- ja mängituslaulud on lastevanemate hulgas levinud kogu maailmas (Trehub \& Trainor 1998) ja on vanemate repertuaaris kindlalt esikohal (Ilari \& Moura \& Bourscheidt 2011). Kuigi hällilaulud on kultuuriti erinevad, on kuulajad võimelised eristama erinevate maade hällilaule mittehällilauludest (Trehub \& Unyk \& Trainor 1993a). Eesti vanemas rahvalaulus oli hällilaul üldiselt lüüriline ja sisult optimistlik ning koosnes kolmest komponendist: sõnast, muusikast ja rütmilistest liigutustest. Hällide erinevad tüübid mõjutasid hällilaule: vibuhälli asendumine jalashälliga kaotas hällilaulude rütmilise paindlikkuse (Tampere 1958: 140-142). Äiutused olid improvisatsioonilised, kasutati tähendusteta sõnu (Rüütel 1998). Ent ema võis last kiigutades laulda ka seda, mis talle endale sel hetkel meeldis. Retsitatiivse iseloomuga regiviis on universaalne ja sobib ka hällilauluks (Vissel 1996). Hällilauludes leiavad väljendust ema tunded, emotsioonid ja lootused lapse suhtes (Tampere 1958: 140). Mari Sarv (2013: 165-170) on eesti hällilaule liigitanud järgnevalt: a) laulud, mis soovivad lapse kiiremat kasvamist, et lapsest oleks abi talutöödes; b) laulud, kus soovitakse lapse kiiremat magamajäämist; c) süngemad laulud stiilis "maga surma poole"; d) kiigutamisega seotud laulud; e) laulud, kus kiidetakse häid lapsi ja ähvardatakse halbu. Samalaadseid hällilaulutüüpe võib leida terves maailmas (Trehub \& Trainor 1998; Sikora \& Żebrowska 2013), nende hulgas ka süngemaid (Honig 1985; Marder 2014).

Tänapäeval on hällilaulu funktsioon Eestis säilinud, kuid hällilaulu repertuaar on muutunud. Lapsevanemad laulavad traditsioonilisi lastelaule, mis pärinevad sageli 20. sajandi alguskümnendite koolilaulikutest. Kõige populaarsemad on 1960.-1970. aastate "Entel-tenteli" lauluvõistluselt pärit laulud (Vissel 2004: 29). Spetsiaalsete hällilaulude kadumise põhjuseks on ilmselt see, et lapsevanem lauluvalikuga ei tegele, talle piisab, kui ta oskab laulda "ühe ilusa laulu”. Nii sarnaneb hällilaul pigem muinasjutule (Vissel 1996). Hällilaul on Eestis tänapäeval sageli asendunud sõnaga "unelaul”, mille populariseerijaks on Tambergi "Karumõmmi unelaul" "Entel-tenteli" lauluvõistluselt (Vissel 2005: 127-128). Olenevalt teksti ja viisi vahekorrast on võimalik eristada lapsevanemate hällilauludes kolme erinevat rühma improvisatsioone: 1) muusikaline improvisatsioon (häälikul, silbil või äiutussõnal) ilma tekstita; 2) enda väljamõeldud tekst tuntud laulu viisil; 3) omaloomingulised on nii sõnad kui viis (Vissel 1996).

Mängituslaulu ülesanne on vastupidiselt unelaulule ergutamine ja rõõmsa meeleolu loomine (Tampere 1958: 143). See on laululiik, mille kaudu arendatakse väikelapse verbaalset ja muusikalist taju ning koordinatsiooni (Vissel 1996). Mängituse puhul on tegemist täiskasvanu ja lapse ühise mänguga, mida 
täiskasvanu juhib ja suunab (Oras 1996). Hällilaulule üsna lähedased on need mängituslaulud, mida lauldakse last põlvel hüpitades, sõitmist või ratsutamist imiteerides ja kus lapse roll on üsna passiivne. Sageli on need seotud lapsele vajalike toimingute õpetamisega või lihtsamate loodusnähtuste tutvustamise ja seletamisega (Tampere 1958: 143). Ingliskeelsed mängituslaulud õpetavad lisaks tähti ja numbreid (Trehub \& Trainor 1998: 53). Vanemast rahvalaulust pärit mängituslaulud on üks väheseid arhailisi laululiike, mis on lapsevanemate repertuaaris säilinud tänapäevani. Nende säilimise on kindlustanud laulu saatev tegevus. Traditsioonilised mängituslaulud on tänapäeva jõudnud primaarse ehk otsetraditsiooni ja sekundaarse traditsiooni (kooliõpikud, lasteraamatud) kaudu (Vissel 2004: 29). Eesti traditsioonilised mängitused jagunevad mängutegevuste järgi: 1) hüpituslaulud, kus on tegemist korrapärase rütmilise liikumisega, nt põlve peal hüpitamine, tammumine, kõnnitamine jne (nt "Sõitsõit sõtsele"); 2) mängitused kitsamas tähenduses ehk kõik traditsioonilised väikelapse lõbustamised, lapse käte või jalgadega mängimised (nt "Tee kakku", "Kuts karja"); sõrmede, varvaste, näo ja kehaosade lugemised jms (Oras 1996). Populaarsemad Eesti vanemad mängituslaulud olid aastatel 1990 ja 1991 "Sõitsõit sõtsele", "Tii-tii, tihane", "Tee kakku", "Koer läheb karja" (Vissel 1996). Tänapäeval on väikelastele mõeldud mängituslaulud peale perede kasutusel beebikoolides ja lauluringides.

Lapsevanemate repertuaarivalikut mõjutavad nii lauljate sugu kui ka kultuuritaust. Emad laulavad peamiselt hälli- ja mängituslaule, isad enam popmuusikat (Ilari \& Moura \& Bourscheidt 2011). Sandra E. Trehubi, Anna M. Unyki ja Laurel J. Trainori (1993b) mitmes eksperimendis osalenud inglise emakeelega emad laulsid lastele peamiselt lõbustavaid laule, hindi emad aga hällilaule. Uurijate arvates on põhjus erinevates kasvatustraditsioonides. Nimelt on Põhja-Ameerikas komme lapsed viia magama teise tuppa juba enne lapse uinumist, kuid India kasvatustraditsioonis magavad lapsed enamasti vanematega ühes toas ja hällilaulul on väga oluline koht lapse kasvatamisel.

Lastele loetud loitsudest on tänapäevani oma algsel kujul säilinud arstimissõnad. Näiteks "Varesele valu", mida esitatakse retsitatiivselt nagu algseltki. Eesti vanemas rahvalaulus on üsna raske tõmmata piiri lastele lauldavate laulude ja täiskasvanute repertuaari vahele (Rüütel 1998), aga sedasama võib öelda ka tänapäevase lastelaulu kohta. Laulud, mida laulsid lapsed ise, olid eesti vanemas rahvalaulus: a) pöördumised lindude, loomade ja loodusobjektide poole, b) narritamissõnad ja muud naljasalmikesed, c) liisusalmid, d) laulud kitsamas mõttes (sageli samad, mida lauldi lastele) (Rüütel 1998; Särg \& Ilmjärv 2009). Spetsiifilisi lastelaule, mis pole seotud mängimisega, on vähe teada (Rüütel 1998). Ahellaulud muutusid juba 19. sajandil laste repertuaariks (Rüütel 2012: 329). 
Tänapäeva laste laulmise uuringud on keskendunud kahele peamisele oskusele: lapsele tuttavate lastelaulude omandamisele ja improvisatsioonilisele laulmisele (Raju 2015: 318). Laste lauluoskuses on psühholoogiaprofessor John Sloboda (2000: 184-189) märganud järgmisi arenguetappe: 1) 18. elukuu paiku tekib spontaanne lauluoskus; 2) kolmandal eluaastal muutuvad spontaansed laulud pikemaks ja seesmiselt organiseeritumaks; 3) kahe aasta vanuses hakatakse püüdma imiteerida kuuldud lauluosi; 4) kahe-kolmeaastaselt toimub konkreetsete rütmide ja helikõrguste eristamine; 5) kolmanda ja neljanda eluaasta jooksul täiustub lapse järelelaulmise oskus; 6) neljandal eluaastal jääb spontaanne laul harvemaks, oluliseks muutub imitatsioon ning nn popurriide esitamine tuttavatest lauludest; 7) viiendaks eluaastaks on spontaansed laulud peaaegu kadunud.

Tänapäeva Eesti laste repertuaarist võib leida samu lastelaululiike nagu vanemas rahvalauluski. On naljasalme, narritusi ja liisusalme. Piiri laste ja täiskasvanute repertuaari vahel tõmmata on keeruline, lapsed laulavad ka täiskasvanutele mõeldud laule. Vanemate mõju laste repertuaarile on eriti suur väikelapseeas. Eestis aastatel 2010-2012 uuritud nelja- kuni kümneaastaste laste lemmiklauludeks olid peamiselt Eesti heliloojate laulud või hästi omaksvõetud teiste rahvaste laulud (Raju 2015). Laste kasvades hakkab laste muusikalist maitset mõjutama muusikatööstus. Analoogne küsitlus Brasiilia ja California seitsme- ja kaheksa-aastaste laste hulgas näitas, et selle vanuserühma lemmiklaulud olid valdavalt popmuusika hitid, enamasti ingliskeelsed (Ilari \& Habibi 2015). Parim uute lastelaulude tutvustaja, levitaja ja õpetaja on tänapäeval meedia. Seetõttu on Eestis kõige populaarsemad lastelaulud nii laste kui ka vanemate hulgas pärit kunagiselt televisiooni laste lauluvõistluselt "Entel-tentel” (Vissel 2004: 29). Meedia mõju kodusele repertuaarile on tuntav mujalgi maailmas. Televisioonist pärit repertuaar on populaarne ka näiteks Brasiilia kodudes (Ilari \& Moura \& Bourscheidt 2011).

Folkloorset ja tänapäevast lastelaulu eristab esitusviis. Kui folkloorset lastelaulu esitati algupäraselt ilma fikseerunud meloodiata (Rüütel 1998), siis tänapäevane lastelaul on enamasti laul selle tavapärases mõttes. Ainult mängituslaule esitatakse retsitatiivselt (Vissel 1996). Varafolkloorseid vokaalžanre ja regilaulu iseloomustab meloodia astmelisus, mis ei ole valdav tänapäeva lastelauludes. Kaasaja lastelauludele on väga iseloomulik tertsides liikumine, mida muusikaõpetuse metoodika on juba aastakümneid rõhutanud. Kuigi uusi lastelaulikuid antakse välja üsna palju ja nad sisaldavad valdavalt uudisloomingut, iseloomustab eesti lastelaulu jätkuvalt traditsioonilisus. Tiina Selke (2007: 104) võrdles 2002. aasta algklasside lauluvara eelnevate aastatega. 2002. aasta lauluvaras 16-st laulust 8 ehk $50 \%$ on pärit 1940. aastate koolide ühislauluvara nimekirjast, 4 laulu ehk $21 \%$ aga 1921. aasta lauluvarast. 


\subsection{Lapsele laulmine Eesti koduses kasvatuskultuuris aastal 2016}

\section{võrdluses Anu Visseli aastaist 1990-2000 pärineva uurimistöö}

\section{tulemustega}

Artikli autorid viisid 2016. aastal läbi empiirilise uurimistöö, selgitamaks lapsele laulmise positsiooni ja tähendust Eesti koduses kasvatuskultuuris. Andmete kogumiseks koostati kirjalik küsitluskava, tuginedes sealjuures Anu Visseli (1996; 2000; 2004; 2005) uuringutes kasutatud küsimustele ning mitmetele uurimustele mujalt maailmast (vt Trehub \& Trainor 1998; Ilari \& Moura \& Bourscheidt 2011; Trehub \& Unyk \& Trainor 1993a), mis leidsid käsitlemist ka artikli alaosas 2.1. Erinevalt eelnevatest uurijatest sai suurem rõhk asetatud konkreetse repertuaarivaliku põhjuste järele pärimisele. Kuna koduse laulmise juures on väga raske eristada lauljaid ja kuulajaid, on suurem osa küsimusi laulmise sageduse jm kohta esitatud eeldatavat lapse ja vanema ühistegevust silmas pidades, nagu näiteks "Kui sageli te lapsele (lapsega) koos laulate?"

Uuritavateks olid eelkooliealiste laste 190 lapsevanemat viiest Tallinna linna ning viiest Ida-Pärnumaa lasteaiast. Vastajate hulgas oli naisi 88,42\% ja mehi $11,58 \%$. Naiste suure ülekaalu põhjuseks on asjaolu, et küsitluskava saadeti lasteaedade lapsevanemate meililistidesse, kus enamasti on üles antud vaid ühe pereliikme, sagedasti ema kontaktaadress. Ühtekokku 28 küsimust (s.h nii kinnisi kui lahtisi küsimusi) sisaldav küsitluskava oli loodud Google Formi abil. Et mitte muuta küsitlust tehniliselt keerukaks ja anda võimalus ausalt vastata ka neile, kes kodus lapsele ei laula, olid täpsemad repertuaari puudutavad küsimused jäetud mittekohustuslikuks.

Kinniste küsimuste abil saadud andmete analüüsimiseks kasutasime andmetöötlusprogramme SPSS ning Microsoft Excel, analüüsimeetoditena kvantitatiivse uurimisviisi raamesse kuuluvat sagedusanalüüsi ning korrelatsioonanalüüsi. Avatud küsimuste abil saadud informatsiooni analüüsimiseks kasutasime summeerivat kvalitatiivset sisuanalüüsi. Lauluvaliku põhjuste kohta käivate küsimuste puhul on sisukategooriad moodustatud induktiivsel meetodil. Internetiküsitluse eripäraks oli avatud küsimustele antud vastustes ka emotikonide kasutamine, mis said samuti arvesse võetud. Avatud küsimustele antud lühim vastus sisaldaski üksnes üht emotikoni.

Järgnevalt esitame oma uurimistöö tulemused suurelt osalt võrdluses etnomusikoloog Anu Visseli tulemustega tema 1990.-2000. aastail tehtud uurimustest (eelkõige uurimus "Kagu-Eesti kodune (lapsekeskne) laulmistraditsioon aastal 2000"). Kui võimalik, on esitatud ka võrdlus meile teadaolevate rahvusvaheliste uuringute andmetega. Etteruttavalt võib öelda, et enamik kõigi 
uurimuste tulemustest ühtib, mis annab tunnistust ka meie uurimismetoodika (s.t küsitluskava) valiidsusest.

Aastal 2016 oli Eestis kõige valdavam muusikaline tegevus kodus salvestatud muusika (CD-d, internet, raadio, televisioon) kuulamine koos lastega (96,32\% küsitletutest), millele järgneb laulmine (76,85\%) ja tantsimine (70,53\%). Arvestades muusikahariduse vähesust vastajatel $(15,79 \%)$, on üllatavalt palju neid, kes mängivad kodus muusikainstrumente (41,58\%). Samas oli pillimängimist küsitud kogu pere kohta, muusikahariduse olemasolu aga vaid küsitletavate endi kohta. Pilli võivad kodus mängida seega ka küsitletavate pereliikmed, sealhulgas pere teised lapsed, kes pillimängu õpivad. Lapsele laulab meie uuringu järgi kodus eelkõige ema (90,53\% küsitletutest), mida väidavad ka varasemad uuringud teistelt autoritelt (vrd Trehub et al. 1997; Custodero \& Britto \& Brooks-Gunn 2003). Visselil (2005) on ema nimetatud lauljaks 77\% juhtudest, varasematel aastatel koguni 88\% ulatuses. Nagu meil, oli ka Visseli uuringus vanaema lauljana tähtsuselt teisel kohal, kuid nende osakaal oli temal kõigest $30 \%$, meil $67,37 \%$. Isa oli tähtsuselt kolmandal kohal: Visseli uuringus osakaaluga $21 \%$, meil $51,05 \%$. Vanaisa nimetas Visseli uuringus lapsele lauljana vaid $5 \%$, meil $22,11 \%$. Sealjuures on antud küsimuse juures oluline pidada silmas, et kui vastaja peab iseennast kellegagi võrdlema, ei ole tulemus kuigi usaldusväärne. Inimestel on paraku kombeks ennast ilustada. Üllatav on näiteks vastassoost inimeste alahindamine. Nagu näha jooniselt 1, peetakse samast soost inimest suuremaks lastele lauljaks kui vastassoost inimest.

Suurim erinevus vastustes puudutab isa rolli lapsele lauljana. Nimelt nimetab isa lapsele lauljana $77,27 \%$ meestest, aga vaid $47,62 \%$ naistest. Samas ema nimetamisel lauljana erinevad meeste ja naiste vastused vähem. Väga põhjapanevaks antud tulemust pidada ei maksa, kuna meeste osakaal küsitletavate hulgas oli tunduvalt väiksem kui naiste osakaal. Kindlasti annab see siiski aimu vastuste teatud subjektiivsusest.

Kui võrrelda erinevate aastate tulemusi seoses küsimusega, kui vanale lapsele peavad lapsevanemad oluliseks laulda, on vastused Visseliga (2005) laias laastus sarnased (vt tabel 1). Tänu korrelatsioonanalüüsile täheldasime lapse vanuse ja laulmise sageduse vahel keskmise suurusega statistiliselt olulist $\operatorname{seost}(r=0,42)$. Seega võibki väita, et noorematele lastele lauldakse rohkem. See fakt langeb kokku ka teiste autorite varasemate uuringutega (vrd Custodero, Britto \& Brooks-Gunn 2003; Custodero \& Johnson-Green 2003).

Kui sageli lastele kodus lauldakse? Kõige populaarsem vastusevariant (37,89\% vastustest) oli meil "rohkem kui üks kord nädalas, ent mitte iga päev". Teisteks variantideks olid "iga päev; üks kord nädalas või vähem; üks kord kuus või vähem; mitte kunagi”. Mitte kunagi ei laula oma lapsele 4,21\% küsitletavatest. 


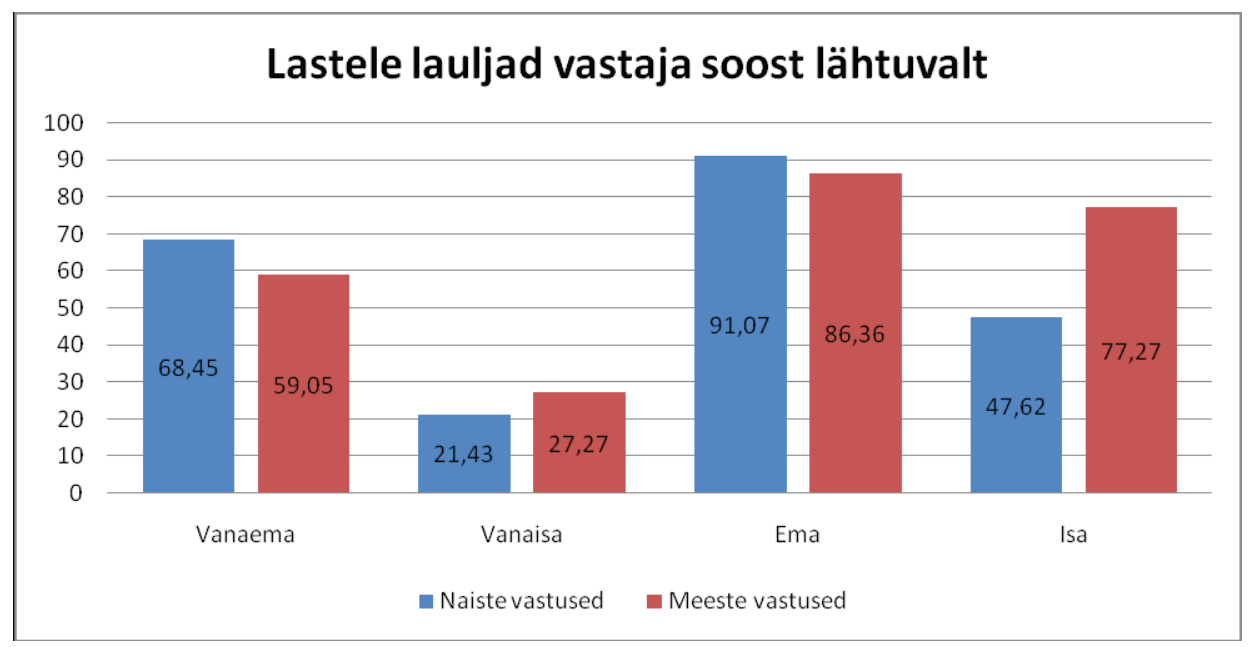

Joonis 1. Lapsele lauljad kodus, vastuste võrdlus lähtuvalt vastaja soost.

Tabel 1. Kui vanale lapsele lauldakse?

\begin{tabular}{|l|l|l|l|}
\hline \multicolumn{3}{|l|}{$\begin{array}{l}\text { Kui vanale lapsele } \\
\text { lauldakse? }\end{array}$} & \multicolumn{3}{l|}{ Uuringu aasta } \\
\hline & $\begin{array}{l}\text { Visseli } \\
\text { varasem } \\
\text { uuring } \\
\text { (aastaarv } \\
\text { teadmata) }\end{array}$ & $\begin{array}{l}\text { Visseli uuring } \\
\text { aastal 2000 }\end{array}$ & $\begin{array}{l}\text { Meie } \\
\text { 2016. aasta } \\
\text { uuring }\end{array}$ \\
\hline Vanusest sõltumata & $46 \%$ & $60 \%$ & $53,68 \%$ \\
\hline Väikelapsele & $34 \%$ & $15 \%$ & $39,47 \%$ \\
\hline $\begin{array}{l}\text { Suuremale, kes ise kaasa } \\
\text { laulab }\end{array}$ & $\begin{array}{l}\text { Vastus } \\
\text { teadmata }\end{array}$ & $15 \%$ & $6,84 \%$ \\
\hline
\end{tabular}

Laulmise sageduse kohta on uuringutes esitatud üsna vastukäivaid andmeid ja see on otseselt sõltunud etteantud vastusevariantidest. Lapsele laulmise sagedust on meil Visseli tulemustega (2005: 125) ka keeruline võrrelda, sest temal olid järgmised vastusevariandid: 1) jah, laulan; 2) laulan, kuid harva; 3) laulan mõni kord nädalas; 4) laulan iga päev. Meie olime oma vastusevariandid nimetanud pigem Pieter de Vries'i (2009) uuringule tuginedes, kus need olid järgmised: 1) iga päev; 2) rohkem, kui üks kord nädalas, ent mitte iga päev; 3) üks kord 
kuus või vähem; 4) mitte kunagi. Samuel A. Mehri 2014. aasta uurimuses oli võimalik vastata lapse laulmise kohta seitsmeastmelisel skaalal, kus vastus "iga päev" oli skaalal järjekorras alles kolmas (skaala algas vastusevariandiga "mitu korda päevas"). Mehr sai populaarseimaks tulemuseks "iga päev" (38\% vastustest), de Vries “üks kord nädalas või vähem” (41\%). Mehr taandas aga oma uuringus seitsmeastmelise skaala de Vries'i neljaastmelisse skaalasse ja võrdles saadud tulemusi, saades nõnda de Vries'i uuringust kardinaalselt erinevad andmed (iga päev laulis siis Mehril 70\% vastanutest, P. de Vries'il vaid $9 \%$ vastanutest). Meie leiame, et selline taandamine ei ole õige ning annab ebaadekvaatsed tulemused. Erinevate küsitluste võrdlusest võib seega järeldada, et kõige rohkem mõjutab tulemusi etteantud vastusevariantide arv. Nii võib antud juhul vaid täheldada, et mitte üheski küsitluses ei olnud kõige populaarsem skaala esimene vastusevariant.

Varasemate tulemustega (vrd Custodero \& Britto \& Brooks-Gunn 2003) langeb kokku fakt, et vastaja vanusel ja laulmise sagedusel ei ole mingit seost ( $r=0,03)$. Kõrgema haridusega inimesed laulavad lapsele rohkem, see tulemus ühtib samuti varasemate uuringutega (vrd samas). Muusikahariduse olemasolul ja lapsele laulmise sageduse vahel on nõrk seos $(r=0,17)$, mis tähendab, et eelnev muusikaharidus mõjutab lapsele laulmist väga vähesel määral. Erinevalt eelmistest uuringutest, kus selgus, et esmasündinuile lauldakse rohkem kui järgmistele lastele peres (vrd Custodero \& Britto \& Brooks-Gunn 2003; Ilari 2005), ei täheldanud meie seost pere laste arvu ja laulmise sageduse vahel $(\mathrm{r}=0,01)$. Korrelatsioonanalüüs kinnitas, et lapse soo ja lapsele laulmise sageduse seos on väga nõrk $(r=0,11)$. Tööhõive ja lapsele laulmise vahel on samuti nõrk negatiivne seos $(r=-0,29)$, millest võib järeldada, et suurema tööhõivega inimesed laulavad lapsele vähem, mis on ka loogiline.

Vastajate hinnangul oma musikaalsusele ja lapsele laulmise sagedusel on keskmine negatiivne seos ( $\mathrm{r}=-0,31)$, mistõttu võime väita, et mida kõrgemaks hindavad vastajad oma musikaalsust, seda rohkem nad lapsele laulavad. Ei saa väita, et mittemusikaalsed inimesed üldse oma lapsele ei laulaks. Kui võrrelda nende vastajate laulmise sagedust, kes hindasid oma musikaalsust hindega 1 või 2 , selgub, et igapäevaseid lauljaid on nende hulgas keskmisest küll vähem 13,51\% (kõikide küsitletavate keskmine 26,84\%), aga samas on siiski märkmisväärne hulk inimesi, kes oma musikaalsust eriti kõrgelt ei hinda, kuid laulavad oma lastele või lastega koos sellest hoolimata.

Meie uurimuses populaarseks osutunud unelaulude võrdlemine Anu Visseli (2004; 2005) varasemate uuringutega näitab, et vähemalt 1990. aastate algusest tänini on populaarsemad unelaulud jäänud samaks. Eino Tambergi "Karumõmmi unelaul"3 oli kõige levinum unelaul ka Visseli kõikide uuringute järgi ning meie teise ja kolmanda koha laulud (Heino Jürisalu "Mina ei taha 
veel magama minna", Pilvi Üllaste "Nuku hällilaul") olid Visseli erinevates uuringutes samuti väga populaarsed. Võrreldes Visseli $(2004 ; 2005)$ erinevate aastate edetabelitega on sinna esikohtadele püsima jäänud viis laulu (lisaks eelnimetatutele veel prantsuse lastelaul "Põdra maja" ja Gustav Ernesaksa "Rongisõit"). Populaarsemate unelaulude positsiooni võrdlust erinevate aastate lõikes vaata tabelist 2. Parema jälgitavuse huvides on eemaldatud autorite nimed ja originaalpealkirjad juhul, kui algussõnad aitavad paremini laulu identifitseerida. Meie uuringus moodustunud edetabeli ülejäänud laulud esinesid ka Anu Visseli tulemustes, kuid need ei olnud kümne kõige populaarsema hulgas. Tõenäoliselt on nende populaarsust unelauludena mõjutanud alates 2001. aastast välja antud erinevad unelaulude plaadid: 2001 "Uinutav beebimuusika", 2004 Ene-Reet Ehala "Unelaulud", 2006 Hedvig Hansoni "Emalaulud", 2006 "Unealbum" ja 2010 "Kaunimad unelaulud". Neil plaatidel on korduvalt esindatud Johannes Brahmsi "Hällilaul”, Bernhard Fliesi "Hällilaul”, Elo Toodo "Unelaul" ja eesti rahvalaul "Viire takka". Nii meie kui Visseli repertuaarinimekirjas ei olnud ühtegi negatiivse alatooniga laulu. Miks? Lapsi on tänapäeva perekonnas vähem ja ka laste suremus on palju väiksem kui nt 18. sajandil. Muutunud arusaamad lapsest ja kasvatusest ei luba ehk enam arvata/kõnelda lapsest midagi negatiivses võtmes. 21 korral nimetati unelauluks ka omaloomingulisi laule, mis näitab omaloomingu küllalt suurt osatähtsust inimeste elus.

Tabel 2. Populaarsemate unelaulude positsiooni võrdlus edetabelites.

\begin{tabular}{|l|l|l|l|l|}
\hline $\begin{array}{l}\text { 1990/1994 } \\
\text { A. Vissel) }\end{array}$ & $\begin{array}{l}\mathbf{1 9 9 6} \\
\text { (A. Vissel) }\end{array}$ & $\begin{array}{l}\mathbf{1 9 9 8 / 1 9 9 9} \\
\text { (A. Vissel) }\end{array}$ & $\begin{array}{l}\mathbf{2 0 0 0} \\
\text { (A. Vissel) }\end{array}$ & $\begin{array}{l}\text { Meie } \\
\text { uurimus } \\
\text { aastast 2016 }\end{array}$ \\
\hline $\begin{array}{l}\text { 1. } \\
\text { Karumõmmi } \\
\text { unelaul }\end{array}$ & $\begin{array}{l}\text { Karumõmmi } \\
\text { unelaul }\end{array}$ & $\begin{array}{l}1 . \\
\text { Karumõmmi } \\
\text { unelaul }\end{array}$ & $\begin{array}{l}\text { Karumõmmi } \\
\text { unelaul }\end{array}$ & $\begin{array}{l}\text { Karumõmmi } \\
\text { unelaul }\end{array}$ \\
\hline $\begin{array}{l}\text { 2. Nuku } \\
\text { hällilaul }\end{array}$ & $\begin{array}{l}\text { 2. Nuku } \\
\text { hällilaul }\end{array}$ & $\begin{array}{l}\text { 2. Nuku } \\
\text { hällilaul }\end{array}$ & $\begin{array}{l}\text { 2. Nuku } \\
\text { hällilaul }\end{array}$ & $\begin{array}{l}\text { 2. Mina ei } \\
\text { taha veel } \\
\text { magama } \\
\text { jääda }\end{array}$ \\
\hline $\begin{array}{l}\text { 3. Põdra } \\
\text { maja }\end{array}$ & $\begin{array}{l}\text { 3. Mina ei } \\
\text { taha veel } \\
\text { magama } \\
\text { jääda }\end{array}$ & $\begin{array}{l}\text { 3. Mina ei } \\
\text { taha veel } \\
\text { magama } \\
\text { jääda }\end{array}$ & $\begin{array}{l}\text { 3. Mina ei } \\
\text { taha veel } \\
\text { magama } \\
\text { jääda }\end{array}$ & $\begin{array}{l}\text { 3. Nuku } \\
\text { hällilaul }\end{array}$ \\
\hline
\end{tabular}




\begin{tabular}{|c|c|c|c|c|}
\hline $\begin{array}{l}\text { 1990/1994 } \\
\text { (A. Vissel) }\end{array}$ & $\begin{array}{l}1996 \\
\text { (A. Vissel) }\end{array}$ & $\begin{array}{l}\text { 1998/1999 } \\
\text { (A. Vissel) }\end{array}$ & $\begin{array}{l}2000 \\
\text { (A. Vissel) }\end{array}$ & $\begin{array}{l}\text { Meie } \\
\text { uurimus } \\
\text { aastast } 2016\end{array}$ \\
\hline 4. Rongisõit & 4. Rongisõit & $\begin{array}{l}\text { 4. Põdra } \\
\text { maja }\end{array}$ & 4. Une-Mati & $\begin{array}{l}\text { 4. Uinu } \\
\text { vaikselt } \\
\text { mu lind }\end{array}$ \\
\hline 5. Une-Mati & $\begin{array}{l}\text { 5. Põdra } \\
\text { maja }\end{array}$ & $\begin{array}{l}\text { 5. Mutionu } \\
\text { pidu }\end{array}$ & $\begin{array}{l}\text { 5. Kes elab } \\
\text { metsa sees }\end{array}$ & $\begin{array}{l}\text { 5.-7. Viire } \\
\text { takka }\end{array}$ \\
\hline $\begin{array}{l}\text { 6. Mutionu } \\
\text { pidu }\end{array}$ & $\begin{array}{l}\text { 6. Juba } \\
\text { linnukesed }\end{array}$ & $\begin{array}{l}\text { 6. Kes elab } \\
\text { metsa sees }\end{array}$ & $\begin{array}{l}\text { 6. Meie kiisul } \\
\text { kriimud } \\
\text { silmad }\end{array}$ & $\begin{array}{l}\text { 5.-7. Põdra } \\
\text { maja }\end{array}$ \\
\hline $\begin{array}{l}\text { 7. Mina ei } \\
\text { taha veel } \\
\text { magama } \\
\text { jääda }\end{array}$ & $\begin{array}{l}\text { 7. Viisk, põis } \\
\text { ja õlekõrs }\end{array}$ & $\begin{array}{l}\text { 7. Kurg ja } \\
\text { konn }\end{array}$ & $\begin{array}{l}\text { 7. Põdra } \\
\text { maja }\end{array}$ & $\begin{array}{l}\text { 5.-7. Uinu } \\
\text { mu väsinud } \\
\text { lind }\end{array}$ \\
\hline $\begin{array}{l}\text { 8. Kes elab } \\
\text { metsa sees }\end{array}$ & $\begin{array}{l}\text { 8. Uni tule } \\
\text { uksest sisse }\end{array}$ & $\begin{array}{l}\text { 8. Meie kiisul } \\
\text { kriimud } \\
\text { silmad }\end{array}$ & $\begin{array}{l}\text { 8. Tütreke, } \\
\text { väike }\end{array}$ & $\begin{array}{l}\text { 8.-9. Uni, } \\
\text { uni uue kuue } \\
\text { annab }\end{array}$ \\
\hline $\begin{array}{l}\text { 9. Uni, tule } \\
\text { uksest sisse }\end{array}$ & $\begin{array}{l}\text { 9. Kes elab } \\
\text { metsa sees }\end{array}$ & 9. Rongisõit & $\begin{array}{l}\text { 9. Äia-tuia, } \\
\text { lase kiike } \\
\text { käia }\end{array}$ & $\begin{array}{l}\text { 8.-9. } \\
\text { Rongisõit }\end{array}$ \\
\hline $\begin{array}{l}\text { 10. Viisk, } \\
\text { põis ja } \\
\text { õlekõrs }\end{array}$ & $\begin{array}{l}\text { 10. Küll on } \\
\text { kena kelguga }\end{array}$ & 10. Võilill & $\begin{array}{l}\text { 10. Juba } \\
\text { linnukesed }\end{array}$ & $\begin{array}{l}\text { 10. Kiisu läks } \\
\text { kõndima }\end{array}$ \\
\hline
\end{tabular}

Küsimus "Miks Te laulate just selliseid unelaule?" ei olnud kohustuslik ja küsimusele vastas $82,63 \%$ küsitletavatest (156 respondenti 190-st). Nimetatud põhjustest moodustusid järgmised suuremad sisurühmad: a) laulu meeldivus kas lapsevanemale (35) või lapsele (29) (kokku 64 vastajat), b) laulja lauluoskuse tõttu valitud laulud (60 vastajat, kes väitsid, et muud ei oska, see laul on meeles, tean laulusõnu, oskan peast laulda, tulevad lihtsalt pähe, endale tuttav); c) laulja lapsepõlvest pärit laulud või on lapsevanemale endale neid 
lauldud: neid laulis mulle mu ema, neid lauldi ka mulle jt (kokku 47 vastajat); d) funktsionaalsed laulud (13), kui vastati, et see unelaul on rahustav, on unele suigutav, see on osa unerituaalist, loob turvatunde; e) laulu tuntus või populaarsus (5); f) laul on õpitud koolis või lasteaias (4) või CD-lt (1); g) laulu seotus kindla isiku ja emotsiooniga (1); h) lapse identiteedi loomine (1) omaloomingulise laulu abil, põhjuseks soov laulda just lapsest endast. Nõnda muutub hällilaul isikulauluks, mis on olnud eriti levinud Põhja-Siberis ja Ameerika põlisrahvuste hulgas. Näiteks nganassaanidele on iseloomulik luua oma lapsele tema isiklik laul, mis räägib temast (Ojamaa 2003). Enamasti on konkreetse laulu laulmisel olnud ühtaegu mitmeid põhjusi. Näiteks edetabelis esikohal oleva "Karumõmmi unelaulu" laulmise põhjustena on nimetatud nii selle laulmise oskust, laulu meeldivust, funktsionaalsust; et see on pärit lapsepõlvest ja lauldud juba praegusele lauljale endale.

Kui võrrelda meie uuringu mängituslaulude edetabelit Visseli 1996. aasta tulemustega, siis Visseli järjestus koosnes üksnes neljast vanast mängituslaulust meie üheksa nimetuse vastu. Samas on neis kahes antud uuringus siiski palju kokkulangevusi (vt tabel 3).

Tabel 3. Populaarsemad mängituslaulud eri aastatel.

\begin{tabular}{|l|l|}
\hline Visseli 1996. aasta uuring & Meie 2016. aasta uuring \\
\hline 1. Sõit-sõit sõtsele & 1. Sõit-sõit sõtsele \\
\hline 2. Tii-tii, tihane & 2. Tee kakku \\
\hline 3. Tee kakku & 3.-5. Kuts läeb karja \\
\hline 4. Koer läheb karja & 3.-5. Põdra maja \\
\hline & 3.-5. Sile tee \\
\hline & 6. Rongisõit \\
\hline & 7. Tii-tii tihane \\
\hline & 8. Hiiretips \\
\hline & 9. Kes aias \\
\hline
\end{tabular}

Mängituslaulude hulgas on säilinud kõige enam vanemat rahvalaulu, mis on edasi kandunud otsepärimusena. Mängituslauludeks on lapsevanemad kohandanud ka suure hulga uuemaid autorilaule, kus on säilinud vastavatele traditsioonilistele lauludele iseloomulikke laulutüüpe. Nii on paljud mängituslaulud seotud sõitmisega, loomadega, tähelepanu juhtimisega lapse kehaosadele. Kui hällilaul esindab eelkõige lauljakeskset repertuaari, siis mängituslaulu puhul on oluline laulu funktsionaalsus ja see valitakse vastavalt sellele, mis lapsele 
meeldib ja teda lõbustab. Põhjustena esinesid ka laulja lauluoskus ning asjaolu, et need laulud on pärit laulja lapsepõlvest või on neid lauljale endalegi lauldud. Vastaja lapsepõlve või lapseiga mainiti 20 korral. Neljal korral öeldi, et neid on vastajale laulnud nende vanaema ja neljal korral, et ema. Osad vastused viitavad mitte ainult lapsepõlves kuuldule, vaid asjaolule, et oluline on olnud ka pärimuslik edasikandumine (Sest neid on meie peres kõigile lauldud; suguvõsas levinud).

Eesti vanemast rahvalaulust pärinevatest lapsele loetud loitsudest on säilinud vaid "Varesele valu", mis on väga populaarne ja millest on palju erinevaid versioone. Samas on selle sõnad muutunud tänapäeva inimestele arusaamatuks ja oma haiguse loomadele saatmine võib tekitada võoristust. Nimetati ka nt Olav Ehala "Vitsalaulu" ("Tule tuul ja puhu ära, meie lapse valu"). Samuti luuakse oma loitse. Peamine loitsu kasutamise põhjus on lapse ravimine, tema valu ära ajamine. Üllatav on väheste nimetatud venekeelsete ja eestikeelsete mängituslaulude ja loitsude sarnasus. Vares ja harakas on lindudena olemas nii eesti- kui ka venekeelses loitsus. See paneb mõtlema, kui palju on eesti vanem rahvalaul mõjutatud teiste rahvaste kultuurist. Eesti rahvausundis on mustad linnud seotud surmaga. Vares oli tark nõialind, kes ennustas regivärsilistes rahvalauludes surma või sõda, kuid üldiselt ei olnud ta nii halvaendeline kui ronk ja ennustas pigem äpardusi. Harakas on tekkemuistendi järgi loodud vanakuradi tütre sõrmest või varbast. Harakas oli endelind, kes ennustas pigem halbu sündmusi (Hiiemäe 1996).

Küsitluskavas oli üks avatud küsimus lapsevanema laulurepertuaari päritolu kohta: kust te olete õppinud need laulud, mida te lastele laulate? Vastas 153 respondenti. Vastuste enamikust (80,39\%) võib välja lugeda, et repertuaar on omandatud elu jooksul ilma spetsiaalselt õppimata (ei ole kuskil õppinud, plaatidelt meelde jäänud). Mõned vastajad ei tea, kust nad on laulu õppinud (Ei tea, need on peas). Kui positsioneerida laulude õppimine vastajate elukaarde, siis 75,16\% vastajatest on ühel või teisel viisil maininud, et teatud laulude tundmine on pärit lapsepõlvest. Ei saa ka väita, nagu poleks lapsevanem võimeline õppima uusi laule. Vastustes on märgitud, et on õpitud laule beebikoolist, internetist, karaokest, televiisorist, reklaamidest ja CD-delt (Midagi on oma lapsepõlvest meeles ja internet aitab ka otsida uusi laule). Kui lastelaulude õppimise allikaks on märgitud raamat või plaat, siis kõrvuti uuemate lastelaulude kogumikega (nt "Väikese lapse laulud") nimetatakse laulikuid, kus on sees ka vanemad lastelaulud (nt "Meie lapse lauluraamat"). Paljude vastajate jaoks on internet, plaadid või noodid pärimuse kandjad ja säilitajad, millede abil vana laul uuesti meelde tuletada. (Elu jooksul on külge jäänud, vahel olen mõne laulu sõnu meelde tuletanud internetist otsides; Mõned laulud on teada lapsepõlvest, kuid sõnu on tulnud meenutada interneti abil; Midagi on meeles 
enda lapsepõlvest, juurde olen vaadanud internetist ja värskelt ostsime koos kuulamiseks "Entel-Tenteli” lastelaulude plaadi-seal kõik olemas.).

Kuigi enamik küsitletutest on sündinud 1980. aastatel, on 1960. aastate televisioonisaate "Entel-tenteli" laulud lastevanemate seas siiani väga populaarsed. "Entel-tentel" on täielik fenomen eesti lastelaulumaailmas, sest hilisematest televisiooni lastelaulusaadetest pole ükski nii populaarseks saanud. "Põdra maja" on lapsevanemate seas lausa universaalne lastelaul, sest seda leiab nii hällilaulude kui ka mängituslaulude seast. Lapse enda lauldavat repertuaari mõjutavad kõige rohkem lasteaed või muusikaring. Seda väidab 85,11\% vastanutest. Tunda on ka meedia mõju. Nimelt on 72,34\% küsitletutest nimetanud lapse lauldavateks lauludeks meediast kuuldud laule. Muude vastustena on nimetatud ka lapsehoidja laule, kontserdil ja teatris õpitud laule. Lapse omaloomingut ehk spontaanseid laule on täheldanud 55,85\% vastajatest (vt joonis 2 ).

Vastates küsimusele "Milline vastus iseloomustab teie lapsele (lapsega) laulmist kõige enam?” oli võimalus valida kolme variandi vahel: 1) peamiselt laulan mina ja laps kuulab, 2) laulame koos, 3) peamiselt laulab laps ja mina kuulan. Vastajatest 45,26\% nõustus väitega, et valdavalt lauldakse koos, 32,63\% laulab peamiselt ise ja laps kuulab. Vastajatest 21,05\% väitis, et laulab peamiselt laps.

Kust või kellelt õpitud laule laulab laps?

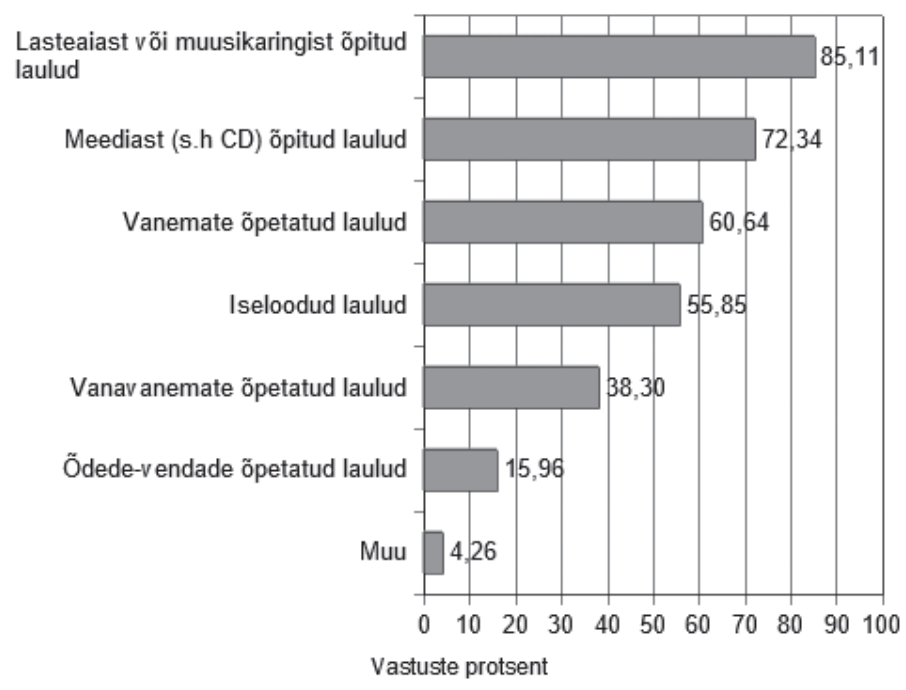

Joonis 2. Lapse laulude päritolu. 
Küsimus ei olnud kohustuslik ja vastamata jättis kaks respondenti (1,05\%). Vastustest võib järeldada, et laulmine kodus on peamiselt ikkagi lapse ja vanema ühistegevus. Huvitav on see, et vastuse "peamiselt laulab laps ja mina kuulan" osakaal oli koguhulgast kõige väiksem. Kui võrrelda aga omavahel erinevaid andmeid - lapsevanema laulmise sagedust, lapse laulmise sagedust ja seda, kes peres rohkem laulab (vanem või laps), siis on näha selget ja vastuolulist lahknevust eri küsimustele antud vastustes. Võib järeldada, et laps laulab kodus lapsevanemast tegelikult ikka rohkem, ent lapsevanem näeb või soovib näha enda osalust selles tegevuses suuremana, kui see on.

\section{Kokkuvõtteks}

Meie 2016. aasta uuringu tulemuste ja Anu Visseli varasemate andmete võrdluse põhjal võib öelda, et lapsele laulmise fenomen on kahtlusteta kultuurisümbol, mis kõneleb suhteliselt püsivaloomulisest üle aegade ulatuvast kodusest kasvatuskultuurist Eestis. See on vaadeldav teadvusliku fenomenina inimeste subjektiivses tegelikkuses (hoiakud ja tähendused, miks üldse lauldakse) ning konkreetse tegevusena kodukeskkondlikus reaalsuses. Ilmneb see kõik aga tänu tegelikkuse kommunikatiivsusele ehk interaktsioonile antud kasvatuskultuuris osalejate vahel - s.t nagu selgus, laulavad laps ja lapsevanem enamasti ikkagi koos, mitte nii, et üks neist laulab ja teine on kuulaja. Lapsevanemad ka tajuvad laulmist lapsele eelkõige dialoogilise ühistegevusena - seda ka siis, kui see päriselt nõnda ei ole. Teadvuslikul tasandil väljendub kommunikatiivsus tänu lauljate seostele kultuurimälu ja sealsete tähendustega. Intersubjektiivne kommunikatsioon kujutab endast alati ka vastavale kultuurile iseloomulike tähenduste mõtestamist ja loomist ning on lisaks ajalisele sünkroniseeritusele ka diakrooniline, sest tegutsetakse ju ajalooliselt kujunenud kultuuriliste tähenduste ruumis. Võib öelda, et enne reaalselt kõnelema hakkamist üks kultuuriline teadvus kõneleb juba teisega (vrd nt Thibault 2000; Bahtin 1987: 215-232). Võiks oletada, et kirjeldatud teadvuslikul mehhanismil rajanebki mis tahes pärimuse edasikandumine ühest ajakihistusest teise antud kultuuriruumis kui loomingulises kollektiivses mälus.

Öeldut toetavad meie empiirilisest uurimusest faktid, et lapsevanemate lauluvalik lastele laulmiseks on üldiselt konservatiivne, repertuaar püsinud läbi aastakümnete suhteliselt muutumatuna ja on pärit suurelt osalt laulja enda lapsepõlvest; et enamus repertuaarist on omandatud elu jooksul spetsiaalselt seda õppimata; et laul võib olla mälestuste kandja ja on seotud ka emotsioonidega. Meie tulemusi Anu Visseli andmetega võrreldes selgus, et 
kõige populaarsemad hälli- ja mängituslaulud on olnud perekondades samad nii 2016. aastal kui 1990. aastatel ja ka 2000. aastate algul. Ka internet, CD-d jms on tänapäeval lastelaulude kontekstis lõppkokkuvõttes pärimuse kandjad, mille abil vana ja ununenud laul meelde tuletada. Seega ei peitu konkreetse laulu valiku põhjused laulus endas (selle noodikirjas või tekstis), vaid laulu ümbritsevas kultuurilises kontekstis ning tema tähenduses lapsevanematele kui lauljatele.

Nagu öeldud artikli esimeses osas, on kasvatuskultuuri "ehituskivideks" vahendatud kasvatustegelikkus, kultuurisümbolid ja rituaalid. Lapsele laulmist kui fenomeni kogu selle komplekssuses on raske pidada rituaalseks fenomeniks (vähemalt selle uurituse praegusel tasemel), ehkki eespool nimetatud rituaali iseloomustavatest tunnustest paljud on siin esindatud. Lapsele laulmine väljendab liikumisteed kollektiivse kultuurimälu ja sünkroonse sotsiaalse tegelikkuse vahel. See taastoodab regulaarse tegevusena kultuurimälu, olles samas igal hetkel aga "valmis" võimalikuks plahvatuslikuks teisenemiseks, väljendades sealjuures ühtaegu nii "vanu" kui ka "uusi" väärtusi. Lapsele laulmise juures põimuvad virtuaalne ja nn reaalne tegelikkus. See kasvatab kultuurimäluga seotuse kaudu eetilisust, tagab tänu eri põlvkondade sidususele nii füüsilise kui emotsionaalse turvalisuse. Lapsele laulmine on mänguline (eriti mängituslaulude puhul), ekspressiivne ja spontaanne tegevus (eriti seoses omaloominguliste lauludega). Identiteedi kujunemine eeldab mäluloovana teatud tegevuste toimumise reegli- ja korrapärasust, mida võibki lapsele laulmisel täheldada eelkõige unelaulude korral.

Une- ehk hällilaul ongi lapsevanemate repertuaaris läbi aastakümnete ülekaalukalt esimesel kohal. Hällilaulude laulmist võiks ka nimetada rituaaliks kasvatuskultuuris, sest sellega seoses tuleb ilmsiks suurem osa rituaali iseloomustavaid tunnuseid. Hällilauludel on olnud läbi aegade püsiv funktsioon kasvatuskultuuris (uinutada laps magama teda rahustades) ning üksnes neid laule võiks pidada (kasvatus)kultuuriliselt globaalseteks fenomenideks. Muidu haakuvad kultuurisümbolid ikkagi eelkõige lokaalsete kasvatustraditsioonide ja -väärtustega. Edasises uurimistöös oleks oluline ja huvitav välja selgitada, missugused keskkondlikud tegurid ja kommunikatsiooniviisid koduses kasvatuskultuuris aktualiseerivad missuguseid kultuurimälu sisusid ning kas lapse potentsiaalne loomingulisus käesoleval ajahetkel on sõltuvuses ta kultuurimälu avarusest ja tähenduslikkusest tema jaoks, või pole selliseid seoseid võimalik täheldada. 


\section{Kommentaarid}

1 Kogu maailmas on levinud nn universaalne hoidjakeel, mille abil kõik täiskasvanud ja suuremad lapsed suhtlevad alla kolmeaastaste lastega. Hoidjakeele ehk lapsele suunatud kõne (ingl child directed speech ehk CDS) puhul kohandavad täiskasvanud oma keelekasutuse vastavaks lapse keelelisele arengule (Argus 2008: 9). Lapsele suunatud kõne prosoodiline ülesehitus on väga erinev täiskasvanule suunatud kõnest. Hoidjakeeles kasutatakse poollaulvat intonatsiooni, kõrgemaid helisid, suuremat hääleulatust. Iseloomulikud on pikad vokaalid, pausid, lühemad laused ja kordusmotiivid (Fernald \& Simon 1984; Fernald 1989; Mithen 2005: 69). Väikelapsele suunatud kõnes on ka meloodia ja hääletoon sõnumiks. Laps ei ole passiivne vastuvõtja. Uuringud näitavad, et laps eelistab hoidjakeelt tavalisele keelele, reageerides miimika ja emotsioonide ja käitumisega. Seega on see kahepoolne suhtlus (Fernald 1989; 1992). Hoidjakeelele iseloomulikud väljendusvahendid nagu helikõrgus, diapasoon, korduvus suurenevad lapse sünnist kuni nelja kuu vanuseni ja vähenevad lapse 24-kuuseks saamiseni. Kõige pikemaid väljendeid kasutati 24-kuuste lastega ja kõige pikemad pausid olid suhtlemisel vastsündinutega (Bergeson \& Trehub 1999: 52).

${ }^{2}$ Marju Raju ja Jaan Rossi 2015. aasta uurimuse "Sõnadest meloodiani: Juhtumiuuring väikelapse laulmise arengust" järgi laulab uuritav väikelaps ikka nn vanu lastelaule (nt "Põdra maja", "Rongisõit", "Karumõmmi unelaul" jt), mis olid ka Anu Visseli 1990.-2000. aastatel tehtud uurimistööde kohaselt populaarsed.

3 Eino Tambergi "Karumõmmi unelaul" on esmakordselt avaldatud 1964. aastal laulikus "Nõukogude Eesti heliloojate laule mudilastele", ent tuntuks sai "Entel-tenteli" lauluvõistlusel. Heino Jürisalu "Unelaul" on omaaegne Eesti Raadio unelaul lastele, mis on loodud 1960. aastate alguses, mis vahepeal asendati uuema unelauluga, ent mõne aja pärast jõudis taas eetrisse (Roomets 2013). Ka uuem raadio unelaul - Elo Toodo "Unelaul" - on meie uurimuse edetabelisse jõudnud. Pilvi Üllaste "Nuku hällilaul" ja "Kiisu läks kõndima" on avaldatud 1960. aasta laulikus, aga "Nuku hällilaulu" populariseerija oli taas "Entel-tentel". Gustav Ernesaksa "Rongisõit" on pärit 1957. aasta teise klassi muusikaõpikust, aga hiljem on seda avaldatud mitmetes nootides ja CD-del. "Põdra maja" leiab juba 1964. aasta "Meie repertuaaris", ent taas on selle populariseerijaks aastate 1968-1970 populaarne lastelaulusaade "Entel-tentel". Ülejäänud klassikaliste unelaulude populariseerijad on olnud tõenäoliselt mitmed unelaulude CD-d.

\section{Kirjandus}

Argus, Reili 2008. Eesti keele muutemorfoloogia omandamine = Acquisition of morphology in Estonian: Doktoritöö. Tallinn: Tallinna Ülikooli Kirjastus.

Bahtin, Mihhail 1987. Valitud töid. Tallinn: Eesti Raamat.

Bergeson, Tonya \& Trehub, Sandra E. 1999. Mothers' singing to infants and preschool children. Infant Behavior and Development 22, lk 51-64 (doi: 10.1016/S01636383(99)80005-8). 
Corbeil, Marieve \& Trehub, Sandra E. \& Peretz, Isabelle 2013. Speech vs. singing: infants choose happier sounds. Frontiers in Psychology 4, lk 1-25 (doi: 10.3389/fpsyg.2013.00372).

Custodero, Lori A. \& Johnson-Green, Elissa A. 2003. Passing the Cultural Torch: Musical Experience and Musical Parenting of Infants. Journal of Research in Music Education 51 (2), lk 102-114 (doi: 10.2307/3345844).

Custodero, Lori A. \& Britto, Rebello Pia \& Brooks-Gunn, Jeanne 2003. Musical lives: A collective portrait of American parents and their young children. Journal of Applied Developmental Psychology 24 (5), lk 553-572 (doi: 10.1016/j.appdev.2003.08.005).

Danesi, Marcel \& Perron, Paul 2005. Kultuuride analüüs. Tallinn: Valgus.

de Vries, Pieter 2009. Music at home with the under fives: what is happening? Early Child Development and Care 179 (4), lk 395-405 (doi: 10.1080/03004430802691914).

Dissanayake, Ellen 2001. Aesthetic Incunabula. Philosophy and Literature 25 (2), lk 335-346 (doi: 10.1353/phl.2001.0026).

Fernald, Anne 1989. Intonation and Communicative Intent in Mothers' Speech to Infants: Is the Melody the Message? Child Development 12 (1), lk 1497-1510 (doi: 10.2307/1130938).

Fernald, Anne 1992. Human Maternal Vocalizations to Infants as Biologically Relevant Signals: An Evolutionary Perspective. Barkow, Jerome \& Cosmides, Leda \& Tooby, John (toim). The Adapted Mind: Evolutionary Psychology and the Generation of Culture. Oxford: Oxford University Press, lk 391-444.

Fernald, Anne \& Simon, Thomas 1984. Expanded intonation contours in mothers' speech to newborns. Developmental Psychology 20 (1), lk 104-113 (doi: 10.1037/00121649.20.1.104).

Harkness, Sara \& Super, Charles M. 2001. Culture and Parenting. Bronstein, Marc H. (toim). Handbook of Parenting: Volume 2. Mahwah: Lawrence Erlbaum Associates, lk 253-280.

Hiiemäe, Mall 1996. Nelikümmend lindu eesti rahvausundis I. Mäetagused 1 \& 2, lk 7-23 (doi: 10.7592/MT1996.01/02.linnud).

Honig, Alice Sterling 1985. Singing with Infants and Toddlers (http://eric.ed.gov/fulltext/ ED352184.pdf - 21. märts 2020).

Ilari, Beatriz 2005. On Musical parenting of young children: musical beliefs and behaviors of mothers and infants. Early Child Development and Care 175 (7-8), lk 647-660 (doi: 10.1080/0300443042000302573).

Ilari, Beatriz \& Moura, Auro \& Bourscheidt, Luis 2011. Between interactions and commodities: musical parenting of infants and toddlers in Brazil. Music Education Research 13 (1), lk 51-67 (doi: 10.1080/14613808.2011.553277).

Ilari, Beatriz \& Habibi, Assal 2015. Favorite songs, melodic elements, and a familiar tune: Performance of children from Brazil and the United States on components of the ATBSS. Musicae Scientiae 19 (3), lk 265-281 (doi: 10.1177/1029864915597566). 
Kellermann, Ingrid 2006. Becoming a pupil: rituals and ritualisation in elementary education. Werler, Tobias \& Wulf, Christoph (toim). Hidden Dimensions of Education: Rhetoric, Rituals and Anthropology. Münster \& New York \& München \& Berlin: Waxmann, lk 105-115.

Kraav, Inger 1998. Väärtused erinevate põlvkondade elus. Mikk, Jaan (toim). Väärtuskasvatus. Tartu: Tartu Ülikooli pedagoogika osakond, lk 72-93.

Lahikainen, Anja Riitta \& Punamäki, Raija-Leena \& Tamminen, Tuula (toim) 2008. Kulttuuri lapsen kasvattajana. Helsinki: WSOY.

Liimets, Airi 1999. Postmodernismi retseptsioonist kasvatusteaduses ehk kas kasvatus olemisel ka eesti keeles laseb kõnelda. Liimets, Airi (toim). Quo vadis, kasvatusteadus? = Quo vadis, educational science? Tallinn: Tallinna Pedagoogikaülikool, lk 98-119.

Liimets, Airi 2004. Õppimine kui tegevus Eesti õpilaste elustiilis 1975-1998. Liimets, Airi \& Ruus, Viive-Riina (toim). Oppimine mitmest vaatenurgast (Acta Universitatis Scientiarum Socialium et Artis Educandi Tallinnensis: A24 Humaniora). Tallinn: Tallinna Pedagoogikaülikool, lk 34-59.

Liimets, Airi 2009. (Muusika)kasvatus kui inimese ja olemise diferents. Liimets, Airi (toim \& koost). Muusikalise kontegelikkuse ühendused identiteedi ja diferentsiga. Tallinn: Tallinna Ülikool, lk 385-396.

Loewy, Joanne \& Stewart, Kristen \& Dassler, Ann-Marie \& Telsey, Aimee \& Homel, Peter 2013. The effects of music therapy on vital signs, feeding, and sleep in premature infants. Pediatrics 131 (5), lk 902-918 (doi: 10.1542/peds.2012-1367).

Lotman, Juri 1991. Kultuurisemiootika: tekst-kirjandus-kultuur. Tallinn: Olion.

Lotman, Juri 1999. Semiosfäärist. Tallinn: Vagabund.

Lotman, Juri 2005. Kultuur ja plahvatus. Tallinn: Varrak.

Luhmann, Niklas 2009. Sotsiaalsed süsteemid. Tartu: Ilmamaa.

Marder, Jenny 2014. Why are so many lullabies also murder ballads? PBS Newshour (http://www.pbs.org/newshour/updates/many-lullabies-murder-ballads/ - 21. märts 2020).

Mattig, Ruprecht 2006. Pop concerts as modern religious rituals: anthropological considerations on a new form of religion. Werler, Tobias \& Wulf, Christoph (toim). Hidden Dimensions of Education: Rhetoric, Rituals and Anthropology. Münster \& New York \& München \& Berlin: Waxmann, lk 152-163.

Mehr, Samuel A. 2014. Music in the Home: New Evidence for an Intergenerational Link. Journal of Research in Music Education 62 (1), lk 78-88 (doi: 10.1177/0022429413520008).

Midtsundstad, Jorunn H. 2006. Communication in the "school-home conference" observed as ritual. Werler, Tobias \& Wulf, Christoph (toim). Hidden Dimensions of Education: Rhetoric, Rituals and Anthropology. Münster \& New York \& München \& Berlin: Waxmann, lk 125-134. 
Mithen, Steven 2005. The Singing Neanderthals: The Origins of Music, Language, Mind, and Body. Cambridge \& Massachusetts: Harvard University Press.

Nentwig-Gesemann, Iris 2006. The ritual culture of learning in the context of family vacation: a qualitative analysis of vacation pictures. Werler, Tobias \& Wulf, Christoph (toim). Hidden Dimensions of Education: Rhetoric, Rituals and Anthropology. Münster \& New York \& München \& Berlin: Waxmann, lk 135-148.

Ojamaa, Triinu 2003. Elulugu muusikas: nganassaani autobiograafilise sisuga laulud. Mäetagused 23, lk 95-113 (doi: 10.7592/MT2003.23.ojamaa).

Oras, Janika (koost) 1996. Mängitus. Folklore.ee (http://www.folklore.ee/rl/pubte/ee/cf/ mjap/janika.html - 21. märts 2020).

Orn, Jüri 1998. Meie kasvatustegelikkuse väärtusest. Kuurme, Tiiu \& Laherand, Meri-Liis (toim). Õpetaja ja õpilane kasvatustegelikkuses. Tallinn: Tallinna Pedagoogikaülikool, lk 9-18.

Puolimatka, Tapio 1999. Kasvatuksen mahdollisuudet ja rajat: Minuuden rakentamisen filosofia. Helsinki: Kirjayhtymä OY.

Raju, Marju 2015. Some aspects of singing development, the song creating process and favorite songs of Estonian children. Doktoritöö. Tallinn: Eesti Muusika- ja Teatriakadeemia.

Raju, Marju \& Ross, Jaan 2015. Sõnadest meloodiani: Juhtumiuuring väikelapse laulmise arengust. Keel ja Kirjandus 58 (5), lk 316-332.

Roomets, Kaja 2013. Vikerraadio õhtujutt kestab seni, kuni Eestis lapsi sünnib. Õhtuleht, 13. august (https://elu.ohtuleht.ee/539958/vikerraadio-ohtujutt-kestab-seni-kuni-eestislapsi-sunnib - 21. märts 2020).

Rüütel, Ingrid 1998. Varafolkloorsetelt vokaalžanridelt lauluni. Mäetagused 8, lk 80-95 (doi: 10.7592/MT1998.08.ing).

Rüütel, Ingrid 1999. Varafolkloorsetelt vokaalžanridelt lauluni III. Mäetagused 10, lk 90-105 (doi:10.7592/MT1999.10.rtl).

Rüütel, Ingrid 2012. Eesti uuema rahvalaulu kujunemine. Tartu: Eesti Kirjandusmuuseumi Teaduskirjastus.

Sarv, Mari 2013. Traditional Estonian lullabies: A tentative overview. Laineste, Liisi \& Brzozowska, Dorota \& Chłopicki, Władysław (toim). Estonia and Poland: Creativity and tradition in cultural communication: Volume 2: Perspectives on national and regional identity. Tartu: ELM Scholarly Press, lk 161-176 (doi: 10.7592/EP.2.sarv).

Selke, Tiina 2007. Suundumusi eesti üldhariduskooli muusikakasvatuses 20. sajandi II poolel ja 21. sajandi alguses. Doktoritöö. Tallinn: Tallinna Ülikooli Kirjastus.

Sikora, Kazimierz \& Żebrowska, Barbara 2013. Traditional Polish lullabies. Laineste, Liisi \& Brzozowska, Dorota \& Chłopicki, Władysław (toim). Estonia and Poland: Creativity and tradition in cultural communication: Volume 2: Perspectives on national and regional identity. Tartu: ELM Scholarly Press, lk 177-190 (doi: 10.7592/EP.2.sikora. zebrowska). 
Silvén, Maarit \& Kouvo, Anna 2008. Onko läheisillä perhesuhteilla kauaskantoisia vaikutuksia lastemme elämään? Lahikainen, Anja Riitta \& Punamäki, Raija-Leena \& Tamminen, Tuula (toim). Kulttuuri lapsen kasvattajana. Helsinki: Werner Söderström Osakeyhtiö, lk 98-116.

Sloboda, John Anthony 2000. Muusikaline meel. Kognitiivne muusikapsühholoogia. Tallinn: Scripta Musicalia.

Sonesson, Göran 1999. The life of signs in society and out of it. Torop, Peeter \& Lotman, Mihhail \& Kull, Kalevi \& Pärli, Ülle (toim). Sign Systems Studies 27. Tartu: Tartu University Press, lk 107-127.

Street, Alison \& Young, Susan \& Tafuri, Johannella \& Ilari, Beatriz 2003. Mothers' attitudes to singing to their infants. Proceedings of the 5th Triennial ESCOM Conference. Hannover: Hanover University of Music and Drama, lk 628-631.

Särg, Taive 2002. Rahvamuusika mõiste kujunemisest "rahva" teaduste ja musikoloogia vahel. Ojamaa, Triinu \& Rüütel, Ingrid (toim). Pärimusmuusika muutuvas ühiskonnas 1. Tartu: Eesti Kirjandusmuuseumi etnomusikoloogia osakond, lk 9-44.

Särg, Taive \& Ilmjärv, Koidu 2009. Eesti rahvamuusika. Folklore.ee (http://www.folklore. ee/muusika/eesti_rahvamuusika.htm - 21. märts 2020).

Tampere, Herbert 1958. Eesti rahvalaule viisidega III. Tallinn: Eesti Riiklik Kirjastus.

Thibault, Paul John 2000. The Dialogical Integration of the Brain in Social Semiosis: Edelmann and the Case for Downward Causation. Mind, Culture, and Activity 7 (4), lk 291-311 (doi: 10.1207/S15327884MCA0704_04).

Trainor, Laurel J. \& Clark, Elissa D. \& Huntley, Anita \& Adams, Beth A. 1997. The acoustic basis of preferences for infant-directed singing. Infant Behavior and Development 20 (3), lk 383-396 (doi: 10.1016/S0163-6383(97)90009-6).

Trehub, Sandra E. \& Unyk, Anna M. \& Trainor, Laurel J. 1993a. Adults identify infantdirected music across cultures. Infant Behavior and Development 16 (2), lk 193-211 (doi: 10.1016/0163-6383(93)80017-3).

Trehub, Sandra E. \& Unyk, Anna M. \& \& Trainor, Laurel J. 1993b. Maternal singing in cross-cultural perspective. Infant Behavior and Development 16 (3), lk 285-295 (doi: 10.1016/0163-6383(93)80036-8).

Trehub, Sandra E. \& Hill, David S. \& Kamenetsky, Stuart B. 1997. Parents' sung performances for infants. Canadian Journal of Experimental Psychology: Revue canadienne de psychologie expérimentale. Special Issue: Music Cognition and Performance 51 (4), lk 385-396 (doi: 10.1037/1196-1961.51.4.385).

Trehub, Sandra E. \& Unyk, Anna M. \& Kamenetsky, Stuart B. \& Hill, David S. \& Trainor, Laurel J. \& Henderson, Joanna L. et al. 1997. Mothers' and fathers' singing to infants. Developmental Psychology 33, lk 500-507 (doi: 10.1037//0012-1649.33.3.500).

Trehub, Sandra E. \& Trainor, Laurel J. 1998. Singing to Infants: Lullabies and Play Songs. Advances in Infancy Research 12, lk 43-77 (http://trainorlab.mcmaster.ca/ publications/pdfs/trainor_trehub.pdf - 21. märts 2020). 
Vissel, Anu 1996. Traditsiooniga ühel pool? Mängult päriselt. Tänapäeva folkloorist II. Tartu: Eesti Keele Instituut, lk 79-103 (http://www.folklore.ee/rl/pubte/ee/cf/mjap/anu. html - 21. märts 2020).

Vissel, Anu 2000. Mida lauldakse lastele eesti kodudes tänapäeval?: Laste endi arvamus. Rüütel, Ingrid (toim). Pärimus pärijaile. Tartu: Eesti Folkloorinõukogu ja Eesti Kirjandusmuuseumi etnomusikoloogia osakond, lk 8-31.

Vissel, Anu 2004. Lastepärimus muutuvas ühiskonnas. Tartu: Eesti Kirjandusmuuseum.

Vissel, Anu 2005. Kagu-Eesti kodune (lapsekeskne) laulmistraditsioon aastal 2000: Lauljad ja laulud. Ojamaa, Triinu (toim). Pärimusmuusikast populaarmuusikani. Tartu: Eesti Kirjandusmuuseum, lk 121-144.

Werler, Tobias \& Wulf, Christoph 2006. Hidden dimensions of education: Rhetoric, rituals and anthropology of education. Werler, Tobias \& Wulf, Christoph (toim). Hidden Dimensions of Education: Rhetoric, Rituals and Anthropology. Münster \& New York \& München \& Berlin: Waxmann, lk 7-11.

Wulf, Christoph \& Zirfas, Jörg 2004. Performative Welten: Einführung in die historischen, systematischen und methodischen Dimensionen des Rituals. Wulf, Christoph \& Zirfas, Jörg (toim). Die Kultur des Rituals: Inszenierungen. Praktiken. Symbole. München: Wilhelm Fink Verlag, lk 7-45.

Wulf, Christoph 2006. Towards a historico-cultural anthropology of education. Werler, Tobias \& Wulf, Christoph (toim). Hidden Dimensions of Education: Rhetoric, Rituals and Anthropology. Münster \& New York \& München \& Berlin: Waxmann, lk 199-208.

Värri, Veli-Matti 2002. Hyvä kasvatus - kasvatus hyvään: Dialogisen kasvatuksen filosofinen tarkastelu erityisesti vanhemmuuden näkökulmasta. Tampere: Tampere University Press.

\title{
Summary
}

\section{The phenomenon of singing to children in the domestic culture of education}

\author{
Airi Liimets \\ Visiting Professor of Philosophy of Education \\ School of Educational Sciences \\ Tallinn University \\ airi_liimets@yahoo.de

\section{Külli Erimäe} \\ Music teacher of Kadaka Kindergarten in Tallinn \\ M.A. in Educational Science (Tallinn University) \\ kyllierimae@gmail.com
}


Keywords: singing to children, children's song, domestic culture of education, empirical analysis, Estonia, comparative analysis

The central question of our research project was: what is the position and significance of the phenomenon of singing to children in the domestic culture of education in today's Estonia? Before answering this question, we have to a) define education as a cultural phenomenon, and b) define singing to children and children's song as cultural phenomena. These are the two aims of our theoretical study. In our empirical research we have additionally sought to find out: a) what can be concluded from the comparison of our data and those of ethnomusicologist Anu Vissel from the 1990-2000, from the perspective of culture of education, and b) whether the results of our empirical research can enrich theoretical treatments of education as a cultural phenomenon.

The article has two parts. The first, "Culture of education - a sign of a communicative educational reality", provides a theoretical analysis of education as a cultural phenomenon. It concludes that the building blocks of culture of education are mediated educational reality, cultural symbols, and rituals. The second major section of the article, "Singing to children in the domestic culture of education", has two sub-sections. The first, "Singing to children and children's song within culture", defines singing to children and children's song as phenomena, building on the work of international scholars and Estonian folklorists. The second subsection, "Singing to children in Estonian domestic culture of education in 2016 in comparison to the results of Anu Vissel's research from 1990-2000", presents the findings of our empirical research.

The data was collected with the help of a written questionnaire, compiled on the basis of the questions used by Anu Vissel in her research and international studies. Differently from previous research, we placed a stronger emphasis on the reasons for choosing a specific repertoire. Our respondents were 190 parents of pre-school children from five kindergartens. The questionnaire that included 28 questions (both closed and open-ended) was created using Google Forms. Answers to the closed questions were analysed with the SPSS and Microsoft Excel software. Our quantitative methods of data analysis included frequency and correlation analysis. Responses to the open-ended questions were analysed using summative qualitative content analysis. In the case of questions concerning song choice content categories were created using the inductive method.

The comparison of our results and those of Anu Vissel allows us to conclude that singing to children is, without a doubt, a cultural symbol that testifies to the existence of a relatively stable domestic culture of education in Estonia. It can be viewed as a phenomenon of consciousness in people's subjective reality (attitudes and meanings attributed to singing) and as a specific activity in the domestic reality. This is manifested owing to the communicativeness of reality or interaction between the participants in the culture of education. That is, our study showed that a child and a parent mostly sing together, instead of one taking the role of the singer and the other that of the listener. Parents also perceive singing to children as a dialogic joint activity, even when it is not that in reality. On the level of consciousness, communicativeness is expressed owing to the singer's connections to cultural memory and meanings therein. Intersubjective 
communication also entails the interpretation and creation of meanings characteristic of culture, and it is both synchronic and diachronic as people operate within a space of historically developed meanings.

The connection to cultural memory can, for example, be seen in the choice of songs sung to children. Parents' song choices are overall conservative and the repertoire has been relatively unchanged across decades and is derived from the singer's own childhood. Most of the repertoire has been acquired through life without special study. The comparison of our and Anu Vissel's results shows that the most popular lullabies and play songs have been the same in families both in 2016 and in the 1990s and early 2000s. The choice of a specific song is not in the song itself (its notes or lyrics) but the cultural context and its significance for the parents as singers.

Over decades lullabies have been the predominant type of song. Singing lullabies could also be called a ritual within local culture of education as it has most of the characteristics of a ritual. Lullabies have had a stable function within the culture of education (lulling to sleep, calming) and only these songs could be viewed as global phenomena of the culture of education. Otherwise cultural symbols are linked to local educational traditions and values. Further research is needed to determine which environmental factors and modes of communication within domestic culture of education actualise which different aspects of cultural memory, and whether the potential creativity of parents today is dependent on the scope and meaning cultural memory has for them or whether these links can be established.

Airi Liimets on Tallinna Ülikooli kasvatusfilosoofia külalisprofessor; samuti Eesti Muusika- ja Teatriakadeemia doktorikooli ja lavakunstikooli külalisprofessor; kasvatusteaduse doktor (Dr. paed) kasvatusfilosoofia alal (2004, Heidelbergi Pedagoogikaülikool). Peamised uurimisvaldkonnad: filosoofiline ja pedagoogiline antropoloogia, kasvatusfilosoofia, noorsoosotsioloogia, üldkasvatusteadus.

Airi Liimets (Dr. paed. in philosophy of education, Heidelberg University of Education 2004) is visiting professor of philosophy of education at Tallinn University and visiting professor at the doctoral school and at the School of Drama at the Estonian Academy of Music and Theatre. Her main fields of research involve philosophical and pedagogical anthropology, philosophy of education, youth sociology, and general educational science.

airi_liimets@yahoo.de 
Külli Erimäe on Tallinna Kadaka lasteaia muusikaõpetaja, kasvatusteaduste magister (2016, Tallinna Ülikool).

Külli Erimäe (MA in Educational Science, Tallinn University 2016) is music teacher at Kadaka kindergarten in Tallinn, Estonia.

kyllierimae@gmail.com 